\title{
Title
}

\section{Long-term ozone exposure and associated cause-specific mortality risks with adjusted metrics by cohort studies: A systematic review and meta-analysis}

\section{Authors}

Haitong Zhe Sun ${ }^{1,2}$, Pei $\mathrm{Yu}^{3}$, Changxin Lan ${ }^{4,5}$, Michelle Wan ${ }^{1}$, Sebastian Hickman ${ }^{1}$, Jayaprakash Murulitharan ${ }^{1}$, Huizhong Shen ${ }^{6}$, Le Yuan ${ }^{1}$, Yuming Guo ${ }^{3 *}$, Alexander Thomas Archibald ${ }^{1,7 *}$

\section{Affiliations}

1 Centre for Atmospheric Science, Yusuf Hamied Department of Chemistry, University of Cambridge, Cambridge CB2 1EW, United Kingdom

2 Department of Earth Sciences, University of Cambridge, Cambridge CB2 3EQ, United Kingdom

3 School of Public Health and Preventive Medicine, Monash University, Melbourne, Victoria 3004, Australia

4 Institute of Reproductive and Child Health, Key Laboratory of Reproductive Health, National Health Commission of the People's Republic of China, Beijing 100191, China

5 Department of Epidemiology and Biostatistics, School of Public Health, Peking University, Beijing 100191, China

6 School of Environmental Science and Engineering, Southern University of Science and Technology, Shenzhen 518055, China

7 National Centre for Atmospheric Science, Cambridge CB2 1EW, United Kingdom

* Correspondence to: Alexander Thomas Archibald (ata27@,cam.ac.uk) and Yuming Guo (yuming.guo@monash.edu)

\section{main-text 4965 words +3 tables +6 figures}




\section{ABSTRACT}

BACKGROUND: Long-term ozone $\left(\mathrm{O}_{3}\right)$ exposure could lead to a series of noncommunicable diseases and increase the mortality risks. However, cohort-based studies were still rather rare, and inconsistent exposure metrics might impair the credibility of epidemiological evidence synthetisation. To provide more accurate meta-estimation, this review updated the systematic review with inclusion of recent studies and summarised the quantitative associations between $\mathrm{O}_{3}$ exposure and cause-specific mortality risks based on unified exposure metrics.

METHODS: Research articles reporting relative risks between incremental long-term $\mathrm{O}_{3}$ exposure and causes of mortality covering all-cause, cardiovascular diseases, respiratory diseases, chronic obstructive pulmonary disease, pneumonia, ischaemic heart diseases, ischaemic stroke, congestive heart failure, cerebrovascular diseases, and lung cancer, estimated from cohort studies were identified through systematic searches in MEDLINE, Embase and Web of Science. Cross-metric conversion factors were estimated linearly by decadal of observations during 1990-2019. DerSimonian and Laird random effect metaregression was applied to pool the relative risks.

RESULTS: A total of 20 studies involving 97,766,404 participants were included in the systematic review. After linearly adjusting the inconsistent $\mathrm{O}_{3}$ exposure metrics into congruity, the pooled relative risks (RR) associated with every $10 \mathrm{nmol} \mathrm{mol}^{-1}$ (ppbV) incremental $\mathrm{O}_{3}$ exposure, by mean of warm-season daily maximum 8-hour average metric, was: 1.010 with 95\% confidence interval (CI) ranging 1.005-1.015 for all-cause mortality; 1.027 (95\% CI: 1.004-1.049) for respiratory mortality; 1.061 (95\% CI: 1.0061.119) for COPD mortality; 1.028 (95\% CI: 1.001-1.058) for cardiovascular mortality; and 1.102 (95\% CI: 1.046-1.162) for congestive heart failure mortality. Positive but insignificant mortality risk associations were found for ischaemic heart diseases, stroke, pneumonia, and lung cancer.

DISCUSSIONS: This review covered up-to-date studies, expanded the $\mathrm{O}_{3}$-exposure associated mortality causes into wider range of categories, and firstly highlighted the issue of inconsistency in $\mathrm{O}_{3}$ exposure metrics. Non-intercept linear regression-based cross-metric RR conversion was another innovation, but limitation lay in the observation reliance, indicating further calibration with more credible observations available. Large uncertainties in the multi-study pooled RRs would inspire more future studies to corroborate or contradict the results from this review. 
CONCLUSIONS: Adjustment for exposure metrics laid more solid foundation for multistudy meta-analysis, the results of which revealed unneglectable cardiopulmonary hazards from long-term $\mathrm{O}_{3}$ exposure.

REGISTRATION: The review was registered in PROSPERO (CRD42021270637).

FUNDING: This study is mainly funded by UK Natural Environment Research Council, UK National Centre for Atmospheric Science, Australian Research Council and Australian National Health and Medical Research Council.

\section{Keywords}

Ozone; long-term exposure; mortality; cohort; metric; respiratory; cardiovascular

\section{Highlights}

1. Updated evidence for $\mathrm{O}_{3}$-mortality associations from 20 cohorts has been provided.

2. Adjusted various $\mathrm{O}_{3}$ exposure metrics can provide more accurate risk estimations.

3. Long-term $\mathrm{O}_{3}$-exposure was associated with increased mortality from all-causes, respiratory disease, COPD, cardiovascular disease and congestive heart failure. 


\section{INTRODUCTION}

Atmospheric ozone $\left(\mathrm{O}_{3}\right)$ is a short-lived climate forcer. ${ }^{1}$ Besides warming the global atmosphere, $\mathrm{O}_{3}$ in the stratosphere can abate the radiation hazards from ultraviolet rays onto organisms, while $\mathrm{O}_{3}$ in the ambient air is of detrimental defects on ecosystem and human health, ${ }^{2-4}$ and hence health effects caused from exposure to surface $\mathrm{O}_{3}$ have become a serious public concern. Short-term (i.e. hours to days) exposure to high-level $\mathrm{O}_{3}$ can cause a series of acute symptoms like asthma, respiratory tract infection, myocardial infarction, and cardiac arrest; ${ }^{5-8}$ and long-term (i.e. over years) exposure can lead to chronic health outcomes including but not limited to preterm delivery, stroke, chronic obstructive pulmonary diseases, and cerebrovascular diseases. ${ }^{9-12}$ Long-term ambient $\mathrm{O}_{3}$ exposure was estimated to be responsible for over 0.36 million premature deaths globally in 2019 in the Global Burden of Disease (GBD). ${ }^{13}$

Systematic reviews summarising the associations between negative health outcomes and $\mathrm{O}_{3}$ exposures, for both the short-term and long-term, have been performed in previous studies. ${ }^{14-16}$ Studies on short-term $\mathrm{O}_{3}$ exposure-induced morbidities are comparatively more abundant than the long-term $\mathrm{O}_{3}$ exposure studies where the epidemiological evidences are less congruous; and some deficiencies are spotted in the two reviews for long-term $\mathrm{O}_{3}$ exposure-associated mortality risk studies, ${ }^{15,16}$ the primary issue of which is the inconsistent use of various $\mathrm{O}_{3}$ exposure metrics. As a secondary photolytic gaseous air pollutant, the warm-season and diurnal concentrations of surface $\mathrm{O}_{3}$ will be much higher than cool-season and nocturnal concentrations, ${ }^{17,}{ }^{18}$ and thus the average and peak metrics of $\mathrm{O}_{3}$ concentrations shall be of drastically different realistic implications. ${ }^{19}$ Under this circumstance, directly pooling the relative risks scaled in different metrics might lead to biases.

Atkinson et al. (2016) explored 6 types of mortality causes, but searched the literatures only till $2015 ;^{16}$ while Huangfu et al. (2019) updated the searches to 2018 , but only 3 types of mortality causes were considered. ${ }^{15}$ We thus determine to update the review on the health effects of $\mathrm{O}_{3}$ to include more categories of mortalities together with covering the most recent publications. Additionally, GBD estimations ascribed long-term $\mathrm{O}_{3}$-exposure induced all-cause mortality for chronic obstructive pulmonary disease, ${ }^{13}$ which might lead to underestimations without considering other causes. It is reasonable to deduce that long-term $\mathrm{O}_{3}$ exposure will exacerbate the mortality of certain diseases given that the short-term exposure increases the morbidity risks of the same diseases, and thus scrutinising epidemiological evidences for multiple causes of mortality will provide more credible supports to fill in this gap. 
To fill the gaps not addressed by the previous two reviews, we updated the systematic review and meta-analysis for long-term $\mathrm{O}_{3}$ exposure and cause-specific mortality risks. We took advantages of global systemic stationary observations to explore the approaches to adjust the various exposure metrics, and pooled the multi-study risks with the unified exposure metric, the mean of warm-season daily maximum 8-hour average, in response to suggestions from the Lancet global environmental health collaboration. ${ }^{20}$

\section{METHODS}

\subsection{Search strategy}

We searched 3 research databases (MEDLINE, Embase, and Web of Science) from 1 September, 2015 till 15 July, 2021 to finish our systematic review and meta-analysis, updated from 2 previous reviews on long-term $\mathrm{O}_{3}$ exposure-associated mortality. ${ }^{15,16}$ Search strategies referred to these 2 previous systematic reviews with modifications as listed in Table S1. Health outcomes considered in the systematic review were: mortality from (1) all causes (AC, ICD9: 001-799, ICD10: A00-R99); (2) all respiratory diseases (RESP, ICD9: 460-519, ICD10: J00-J98); (3) chronic obstructive pulmonary diseases and allied conditions (COPD, ICD9: 490-496, ICD10: J19-J46); (4) all cardiovascular diseases (CVD, ICD9: 390-459, ICD10:I00-I98); (5) all cerebrovascular diseases (CEVD, ICD9: 430-438, ICD10: I60-I69); (6) ischaemic heart disease (IHD, ICD9: 410-414, ICD10: I20-I25); (7) congestive heart failure (CHF, ICD9: 428, ICD10: I50); (8) ischaemic stroke (ICD9: 434, ICD10: I61-I64); (9) pneumonia (ICD9: 480-487, ICD10: J12-J18); and (10) lung cancer (LC, ICD9: 162, ICD10: C33-C34).

\subsection{Study eligibility criteria}

Studies were included during screening following the criteria as: (1) the epidemiological research should be conducted based on cohorts; (2) the exposure should include $\mathrm{O}_{3}$ as an individual risk factor; (3) the health outcomes should be all-cause or cause-specific deaths at individual level; (4) studies provided hazard ratio (HR), risk ratio (RR) or odds ratio (OR) and their 95\% confidence intervals (CIs) clearly and reported by every increase unit (e.g. 10-ppbV) of exposure concentrations, assuming linear risk 
relationship with adjusting key confounders; (6) the study should be published as an original research article in scholarly peer-reviewed journals in English. For articles from the same cohort, only one single study covering the widest populations and the longest follow-up period was reserved for meta-analysis, unless the subgroups of participants and study follow-up periods are clearly stated to be of mild overlapping; We followed the Preferred Reporting Items for Systematic Review and Meta-Analyses (PRISMA) guidelines to process the included studies on ambient $\mathrm{O}_{3}$ exposure induced mortality.

\subsection{Study selection and scrutinisation}

All searched literatures were archived in Clarivate ${ }^{\mathrm{TM}}$ Analytics Endnote X9.3.1 reference manager software. Two literature review investigators (HZS and CL) conducted title and abstract pre-screening independently for all web-searched records and reviewed the full text for the pre-screened studies. Disagreements were resolved by discussions with a third reviewer (PY).

\subsection{Data extraction}

Details from each screened-out literatures were extracted and labelled for the purpose of meta-analysis, including (1) the authors with publication year as study labels of reference; (2) basic descriptive information of the study cohort embracing the cohort name, country, follow-up periods, numbers of cases and total participants, population genders and ethnics, exposure metrics, health outcomes, and major confounders; (3) the risk association effects preferably quantified in HR (and also RR/OR as substitute choices) per unit incremental exposure with 95\% confidence interval (CI).

\subsection{Study quality assessment}

All screened-out studies underwent quality evaluation using the Quality Assessment Tool of Observational Cohort and Cross-Sectional Studies developed by National Institute of Health (NIH) (https://www.nhlbi.nih.gov/health-topics/study-qualityassessment-tools), aiming to ensure the studies considered for meta-analysis are adequately reliable. The assessments were cross-validated by two authors (HZS and CL) independently, with the third author (PY) supervising any disagreements. Table S2 listed 14 assessment items assigned with 1 score for each, and the tallied scores were translated 
into a literature-specific rating of quality. Studies scoring full-mark 14 were categorised to be "Good", while 10-13 as "Fair" and $<10$ as "Poor".

Besides the quality assessment tool to determine which reviewed studies should be included for meta-analysis, characterising the epidemiological evidence quality from the included literatures for each cause of mortality was finished through the Grading of Recommendations Assessment, Development, and Evaluation (GRADE) system ${ }^{21,22}$ to yield rating bands ranging across "high", "moderate", "low", and "very low". This grading system by default rated "high-quality" for cohort studies as the starting point of evaluation, and the rank would be downgraded by five reasons as existence of (1) risk of bias, (2) imprecision, (3) inconsistency, (4) indirectness and (5) publication bias, and upgraded by reporting (1) exposure-response trend, (2) residual confounding, and (3) reporting strong associations. Publication biases were tested by trim-and-fill method. ${ }^{23}$ The review was registered in PROSPERO (CRD42021270637).

\subsection{Exposure adjustment}

\subsubsection{Unit unification}

There were two major units used to quantify the surface $\mathrm{O}_{3}$ concentrations, nmol $\mathrm{mol}^{-1}$ or parts per billion by volume mixing ratio (ppbV) more frequently used by atmospheric modelling researchers, ${ }^{17,18,24}$ and milligram per cubic metre by mass concentration $\left(\mu \mathrm{g} / \mathrm{m}^{3}\right)$ widely used by public health studies. ${ }^{12}$ These two units are interchangeable to each other based on the ideal gas law $P V=n R T$, if the air temperatures $(\mathrm{T})$ and pressures $(\mathrm{P})$ are given, as presented in eqs $1-4$.

$$
\begin{aligned}
& 1 \mathrm{ppbVO}_{3}=\frac{1 \times 10^{-9} \mathrm{~mol}}{1 \mathrm{~mol}} \frac{\mathrm{O}_{3}}{\mathrm{air}} \\
& 1 \mathrm{~mol} \mathrm{air} \Leftrightarrow \frac{R T}{P} \times 1 \mathrm{~mol}\left(\mathrm{~m}^{3}\right)=\frac{8.314 \mathrm{~Pa} \cdot \mathrm{m}^{3} \cdot \mathrm{K}^{-1} \times T}{P}\left(\mathrm{~m}^{3}\right) \\
& 1 \times 10^{-9} \mathrm{~mol} \mathrm{O}_{3} \times 47.997 \mathrm{~g} \cdot \mathrm{mol}^{-1}=47.997 \times 10^{-9} \mathrm{~g} \mathrm{O}_{3} \\
& 1 \mathrm{ppbV} \mathrm{O}_{3}=\frac{47.997 \times 10^{-9} \mathrm{~g} \times 10^{6} \mu \mathrm{g} \cdot \mathrm{g}^{-1}}{8.314 \mathrm{~Pa} \cdot \mathrm{m}^{3} \cdot \mathrm{K}^{-1} \times \mathrm{T} / \mathrm{P} \mathrm{m}^{3}} \frac{\mathrm{O}_{3}}{\mathrm{air}}=5.773 \times 10^{-3} \times \frac{P(\mathrm{~Pa})}{T(\mathrm{~K})} \frac{\mathrm{O}_{3}}{\mathrm{air}} \mu \mathrm{g} \cdot \mathrm{m}^{-3}
\end{aligned}
$$


Assuming $\mathrm{T}=298.65 \mathrm{~K}\left(25.5^{\circ} \mathrm{C}\right)$ and $\mathrm{P}=101.325 \mathrm{kPa}$, the $\mathrm{ppbV}-\mu \mathrm{g} / \mathrm{m}^{3}$ conversion factor could be approximated as $1 \mathrm{ppbV} \sim 1.96 \mu \mathrm{g} / \mathrm{m}^{3}$. Though the surface air temperatures and pressures would vary across seasons, such simplification was still widely used in previous studies, ${ }^{15,25,26}$ being of more credibility for long-term surface $\mathrm{O}_{3}$ studies averaging the surface air temperatures and pressures at longer periods. For example, even at very low temperature of $270 \mathrm{~K}$, the conversion factor was 2.17 , which corroborated the stability of linear conversion.

\subsubsection{Metric unification}

Surface $\mathrm{O}_{3}$, as a secondary photochemistry pollutant involving photolysis of $\mathrm{NO}_{2}$ to trigger chains of radical reactions, has concentrations that will vary significantly between day and night-time, and between warm and cool seasons, as discussed by numbers of studies. ${ }^{17,27-30}$ Under this circumstance, various daily metrics to quantify the surface $\mathrm{O}_{3}$ concentrations emerged due to series of considerations, which however brought in more difficulties to assimilate epidemiological evidences. The previous reviews simply pooled the reported risk association strengths without adjusting the diverse metrics, ${ }^{15,16}$ which we thought was a fatal defect requiring improvements.

We therefore designed to update the meta-analysis by unifying the exposure metrics for pooled $\mathrm{O}_{3}$ exposure-associated risks. As suggested by U.S. EPA final report of Air Quality Criteria for Ozone and Other Photochemical Oxidants, ${ }^{31}$ linear relationships were assumed to estimate the cross-metric conversion factors using long-term reliable observations as the Tropospheric Ozone Assessment Report (TOAR) archive ${ }^{19}$ and China National Environmental Monitoring Centre (CNEMC, http://www.cnemc.cn/en/) in our review, and correlation matrix was used to validate that the presumptions of linearity were not violated. We considered 6 complex metrics for mutual conversion as (1) annual mean of 24-hour daily average (ADA24), (2) 6-month warm season mean of 24-hour daily average (6mDA24), (3) annual mean of daily maximum 8-hour average (ADMA8), (4) 6-month warm season mean of daily maximum 8-hour average (6mDMA8), (5) annual mean of daily maximum 1-hour average (ADMA1), and (6) 6-month warm season mean of daily maximum 1-hour average (6mDMA1). The linear conversion factors $(k)$ were mathematically defined by eq 5 , to adjust the original metric into the target one with irreducible regression errors $\varepsilon$.

$C_{\text {Adjusted }}=k_{\text {Original } \rightarrow \text { Adjusted }} \times C_{\text {Original }}+\epsilon$ 


\subsection{Meta-analysis}

We collectively named relative risks (RR) for HR/RR/OR throughout our metaanalysis. All literature-reported RRs were converted into adjusted incremental risk ratios with a 10-ppbV O3-exposure increase by target metric (i.e. 6mDMA8 in this study), following eq 6 as shown below:

$R R_{\text {Adjusted }}=e^{\left(\frac{\ln R R_{\text {Original }}}{k_{\text {Original } \rightarrow \text { Adjusted }}}\right)}$

where $\ln$ is the natural logarithm, $R R_{\text {Original }}$ is the originally reported risk estimates scaled into $10-\mathrm{ppbV}$ incremental exposure, and $k_{\text {Original } \rightarrow \text { Adjusted }}$ is the conversion factor for metric unification. Multi-study pooled risks with $95 \%$ confidence interval (CI) were calculated from the adjusted RRs by DerSimonian and Laird random effect metaregression given the fact that population and methodologies of included researches differed with each other. ${ }^{32}$

We applied the Higgins $I^{2}$ to quantify the heterogeneity across studies. The Higgins statistics $I^{2}$ is defined as

$I^{2}=\frac{Q-d f}{Q} \times 100 \%$

where $\mathrm{Q}$ is the Cochran's non-parametric heterogeneity statistic assessing whether there are any cross-study differences in risks based on $\chi^{2}$ distribution and $d f$ is the corresponding degrees of freedom. ${ }^{33}$ Low $I^{2}$ values indicate no important heterogeneity observed and high $I^{2}$ values, especially $>75 \%$, indicate considerable heterogeneity.

Subgroup analyses were conducted by grouping the meta-analysis included studies upon the six $\mathrm{O}_{3}$ exposure metrics. One-dropout sensitivity analyses were also accomplished to test the robustness of synthesised overall risks by meta-analysis. All meta-analyses were performed in R 4.1 .1 with packages meta and metafor.

The most widely recognised approach to construct the integrated exposure-response $(\mathrm{IER})^{34}$ relationships required sufficient epidemiological studies to comprehensively sample the population exposure levels. However, studies on long-term $\mathrm{O}_{3}$ exposure health effects were relatively limited, under which circumstance we made methodological modifications to make better use of the variabilities in exposure levels by statistically 
imputing the exposure distributions for each study from the provided statistics (e.g. mean, standard deviation, and percentiles) for curve fitting as elaborated in Supplementary Text S1. Supplementary Text S2 described the detailed procedures of exposure distribution imputations with a demonstration provided in S3, through which high uncertainties were observed in the fitted IER curves due to limited number of available studies.

\section{RESULTS}

\subsection{Study characters}

From the 3 databases during September 2015 till July 2021, a total of 308 studies (70 from MEDLINE, 93 from Embase, and 145 from Web of Science) were searched; and together with 34 additional literatures added manually from the 2 previous systematic reviews, ${ }^{15,16} 342$ studies underwent duplication censoring, deleting 95 duplicated studies. After detailed scrutinisation for 247 studies, a total of 20 studies concerning long-term $\mathrm{O}_{3}$ exposure and multi-cause mortalities were finally enrolled for quality evaluation, metaanalysis and further discussions (Figure 1). ${ }^{35-54}$ Table 1 summarised the basic information of the 20 included studies sorted by the publication year and surname of the first author.

\subsection{Metrics and exposure assignments}

Our updated systematic review stressed more on the exposure metrics and methodologies to obtain $\mathrm{O}_{3}$ exposure, as summarised in Table 2. Abbey et al. (1999), ${ }^{35}$ Jerrett et al. (2013) ${ }^{43}$ and Lipsett et al. $(2011)^{40}$ did not state the metric they used clearly, but based on comparisons between the reported surface $\mathrm{O}_{3}$ concentrations and TOAR observational archives, we reasonably assumed ADA24 for the first study, and ADMA8 for the last two. Details of the metric matching were given in Supplementary Text (S4). Lipfert et al. (2006) ${ }^{36}$ used the highest $95^{\text {th }}$ percentile by hourly resolved $\mathrm{O}_{3}$ concentrations as the peak exposure metric, which was only used in this one singular study, and hence approximated to DMA1. Krewski et al. (2009) ${ }^{38}$ and Smith et al. $(2009)^{39}$ were both studies on ACS CPS II, and thus the same exposure assignment methodologies and metrics were assumed as Jerrett et al. (2009). ${ }^{37}$ Likewise, Cakmak et al. $(2018)^{49}$ and Weichenthal et al. $(2017)^{48}$ were assumed to inherit Crouse et al. $(2015)^{45}$ 
as all these 3 studies were on CANCHEC. Warm season was defined as 6 months from April to September by default, but we made no exceptions to 3 studies as Zanobetti et al. $(2011)^{41}$ using May to September, and Crouse et al. $(2015)^{45}$ and Paul et al. $(2020)^{54}$ using May to October, due to limited number of studies searched.

Across all included studies, multiple methods were applied to assign $\mathrm{O}_{3}$ exposure onto individual-level cohort participants. The most basic way was the nearest neighbour matching between participant residential locations and in situ observation sites, which were more frequently used in earlier studies. ${ }^{36,37}$ A comparatively more complicated way was statistical spatial interpolation, by inverse distance weighting ${ }^{43}$ or ordinary kriging ${ }^{38}$. Full spatial coverage products, such as satellite-based remote-sensing ${ }^{50}$ and chemistry transport models ${ }^{53}$, were used in some studies by data fusion techniques including but not limited to universal kriging, ${ }^{44}$ Bayesian hierarchical mode ${ }^{47}$ and ensemble learning ${ }^{50}$ to enhance the spatial extrapolation accuracy, which were evaluated to be of higher credibility than the basic ones described previously. We also ranked higher the finer spatiotemporal resolved surface $\mathrm{O}_{3}$ concentration datasets for exposure assignments.

Based on the TOAR and CNEMC in situ observations, the cross-metric linear conversion factors were estimated with regression accuracies given in Figure 2. Synthesising from recent relevant studies, the 6mDMA8 metric was recommended to highlight the peak exposure (Table 2); and therefore, we chose to convert the originally reported RRs uniformly into the 6mDMA8 scale as reference. The adjusted RRs for each 10 -ppbV incremental $\mathrm{O}_{3}$ exposure by 6mDMA 8 were listed in Table S3. Demonstrations for the conversion interpretation and procedures were presented in Supplementary Text S5, respectively.

\subsection{Meta-analysis results}

We conducted meta-analyses for long-term $\mathrm{O}_{3}$ exposure-associated into 10 categories of mortalities as (1) all causes (AC), (2) all respiratory diseases (RESP), (3) chronic obstructive pulmonary diseases and allied conditions (COPD), (4) all cardiovascular diseases (CVD), (5) all cerebrovascular diseases (CEVD), (6) ischaemic heart disease (IHD), (7) congestive heart failure (CHF), (8) lung cancer (LC), (9) ischaemic stroke, and (10) pneumonia, with the exposure metrics adjusted into 6mDMA8. 


\subsubsection{All-cause mortality}

A total of 18 studies were included into $\mathrm{O}_{3}$ exposure-associated all-cause mortality meta-analysis, pooling the overall risk into $\mathrm{RR}=1.010$ (95\% CI: $\left.1.005-1.015, \mathrm{I}^{2}: 93.0 \%\right)$ with every $10-p p b V$ incremental exposure by $6 \mathrm{mDMA} 8$ as presented in Figure 3. Subgroup meta-analysis by originally reported metrics concluded the significances of risks vary across metrics, as high-concentration highlighted metrics like 6mDMA8 were of the highest positive risk $(\mathrm{RR}=1.029,95 \% \mathrm{CI}: 1.001-1.061)$ while the smoothed metric ADA24 reported negative association $(\mathrm{RR}=0.992,95 \% \mathrm{CI}: 0.982-1.002)$, as shown in Figure S1. Another sub-group meta-analysis by cohort population ethnics performed significant discrepancies of the risk pattern, as the studies in North America revealed positive associations as $\mathrm{RR}=1.011$ (95\% CI: 1.006-1.016), while researches on European populations showed reversed risks as RR $=0.921$ (95\% CI: 0.869-0.976), as shown in Figure S2. This manifested that high cross-study heterogeneities originated from both metric differentiations and ethnic divergences, the latter of which should have attributed more. The funnel plot was visually symmetrical (Figure S3), and studies reporting risks below the pooled value were slightly more, indicating no severe potential publication biases.

\subsubsection{Respiratory mortality}

Meta-analysis for $\mathrm{O}_{3}$ exposure-associated all respiratory mortality includes 13 studies, pooling gave the overall $\mathrm{RR}=1.027$ (95\% CI: $1.004-1.049, \mathrm{I}^{2}: 82.5 \%$ ) for every 10 -ppbV incremental by $\mathrm{O}_{3}$ exposure 6mDMA8 (Figure 4). Based on sub-group metaanalysis for different metrics (Figure S4), peak metrics showed more significant increasing risks than ADA24, where most of the heterogeneities from $\left(\mathrm{I}^{2}=86.5 \%\right)$. Cross-metric divergences were generally higher than intra-metric discrepancies. Studies on North America populations showed better homogeneity in positive risks $(\mathrm{RR}=1.028$, 95\% CI: $1.011-1.047, \mathrm{I}^{2}=82.1 \%$, Figure S5) than the European cohorts, pooling from which the overall risks were congruously insignificant $(\mathrm{RR}=0.949,95 \% \mathrm{CI}: 0.795-$ $\left.1.131, \mathrm{I}^{2}=18.0 \%\right)$. No apparent positive publication biases were detected according to the funnel plot. For the $\mathrm{O}_{3}-\mathrm{COPD}$ mortality association, pooled $\mathrm{RR}=1.061(95 \% \mathrm{CI}$ : $1.006-1.119, \mathrm{I}^{2}=94.7 \%$ ) for $10-\mathrm{ppbV}$ incremental $\mathrm{O}_{3}$ exposure by 6mDMA8 from 6 studies. 


\subsubsection{Cardiovascular mortality}

A total of 12 studies were included to pool the overall $\mathrm{O}_{3}$ exposure-induced CVD mortality risks as $\mathrm{RR}=1.028\left(95 \% \mathrm{CI}: 1.001-1.058, \mathrm{I}^{2}=97.9 \%\right)$ for each $10-\mathrm{ppbV}$ additional $\mathrm{O}_{3}$ exposure by 6mDMA8 (Figure 5). Heavy heterogeneities $\left(\mathrm{I}^{2}>81.6 \%\right.$ ) were observed through all 4 metric-grouped studies as presented in Figure S6. Positive risk associations were found for 10 North American cohorts $(\mathrm{RR}=1.038,95 \% \mathrm{CI}$ : 1.008-1.068) while oppositely for 2 European cohorts ( $R R=0.936,95 \%$ CI: 0.898 0.975), as shown in Figure S7. Mild positive publication biases were detected, reflecting the actual risk could potentially be lower than the meta-analysis estimation. For congestive heart failure-induced mortality, the pooled risk was $\mathrm{RR}=1.102$ (95\% CI: $1.046-1.162, \mathrm{I}^{2}=88.6 \%$ ) with every $10-\mathrm{ppbV}$ elevated $\mathrm{O}_{3}$ exposure by $6 \mathrm{mDMA} 8$, but might be slightly overestimated by detected positive publication bias.

\subsubsection{Other causes mortality}

The other cause-specific mortality risks attributable to long-term $\mathrm{O}_{3}$ exposure were not statistically significant (Figure 6), as IHD mortality risk pooled from 9 studies was $\mathrm{RR}=1.023$ (95\% CI: 0.992-1.055, $\left.\mathrm{I}^{2}=97.7 \%\right)$, CEVD mortality risk pooled from 5 studies was $\mathrm{RR}=0.997$ (95\% CI: $\left.0.973-1.020, \mathrm{I}^{2}=73.6 \%\right)$, LC mortality risk pooled from 10 studies was $\mathrm{RR}=0.984\left(95 \% \mathrm{CI}: 0.961-1.008, \mathrm{I}^{2}=80.8 \%\right)$, ischaemic stroke mortality risk pooled from 2 studies was $\mathrm{RR}=1.003$ (95\% CI: 0.991-1.016), and pneumonia mortality risk pooled from 3 studies was $\mathrm{RR}=1.034$ (95\% CI: $0.954-1.121)$.

Potential publication biases were discovered for CEVD and lung cancer, though the pooled risks were insignificant, suggesting the authentic risks could moderately deviate from our meta-analysis results. Though we conducted meta-analyses for ischaemic stroke and pneumonia mortality risks, the included studies were rather few with high heterogeneities, and thus it could be improper to conclude no associations between longterm $\mathrm{O}_{3}$ exposure and mortality risks of ischaemic stroke or pneumonia based on the limited evidences collected in our study. For the 8 mortality sub-categories involving no less than 4 studies, we also provided pooled risks by 4 widely used metrics in Table 3.

\subsection{Study assessment}

All 20 studies included into our final meta-analysis were rated to be above "Fair" by the quality assessment tool for observational cohort studies, as listed in Table S4. Tables 
S5 presented GRADE epidemiological evidence assessment results for each mortality cause from all involved corresponding studies. In brief, the overall judgements for allcause, respiratory, and lung cancer mortality risks were "High", for cerebrovascular mortality risk was "Low", and for the rest cause-specific mortality risks were all "Moderate". The assessment results verified the acceptability of our meta-analyses, with more details given in Supplementary Text (S6).

\subsection{Sensitivity analysis}

One-dropout sensitivity analyses showed stable risk estimates as summarised in Table S6, except for the lung cancer mortality risks after eliminating Kazemiparkouhi et al. (2019), the only study reporting positive risk association, ${ }^{52}$ while the rest 9 studies concluded insignificant or negative risks. Since the metric harmonisation in our study was an innovative attempt, we provided both metric-adjusted and unadjusted crude results for reference as presented in Table 3.

\section{DISCUSSIONS}

\subsection{Improvements as an updated review}

This work improves on 2 previous high-quality reviews ${ }^{15}, 16$ by covering up-to-date peer-reviewed studies, and expanding the $\mathrm{O}_{3}$-exposure associated causes of mortality into wider range of categories. It is the first systematic review of the association between long-term $\mathrm{O}_{3}$ exposure and cause-specific mortality highlighting the issue of inconsistent use of exposure metrics to our best knowledge. Since tropospheric $\mathrm{O}_{3}$ is a photochemical pollutant which largely depends on solar radiation, the surface $\mathrm{O}_{3}$ concentrations can vary drastically between day and night, as well as warmer and cooler seasons. We pointed out that a $10-\mathrm{ppbV}$ increase in annual daily 24-hour average concentration (ADA24) is more constrained in magnitude than a 10 -ppbV increase in warm-season daily 8 -hour maximum average concentration (6mDMA8) owing to the wider variability in the range of the latter metric. Taking the observations by TOAR and CNEMC in situ monitoring networks during 1990-2019 as an example, the surface $\mathrm{O}_{3}$ concentrations were 27.6 \pm 6.1 (IQR: 24.1-31.0) ppbV by ADA24, while correspondingly 53.1 \pm 10.6 (IQR: 47.7-61.4) ppbV by 6 mDMA8, which indicated a 10 -ppbV change fell below the IQR by the 
6mDMA8, but could exceed the IQR using the ADA24 metric. This was why we believe adjusting the exposure metrics was necessary for $\mathrm{O}_{3}$ exposure-attributable health risk meta-analysis.

We also put forward a feasible approach to mutually convert the $\mathrm{O}_{3}$ exposure concentrations and corresponding risk strengths in various metrics by non-intercept linear projections following the methodological suggestions from EPA, ${ }^{31}$ but update the linear conversion factors based on global in situ surface $\mathrm{O}_{3}$ observations during 1990-2019. The methodological innovation took advantages of multi-dimensional information from the original studies, but still inspiring further observation collections and researches for corroborations and improvements.

\subsection{Metric relevant issues}

Although linear coefficients were applied onto the cross-metric conversions, irreducible noises still existed given the high root mean squared errors (RMSE) as shown in Figure 2, which exposed the limitation of risk strength adjustment into the same exposure metric by simple linear conversion, as the actual cross-metric relationships could be way more complicated. However, there was no other way but using the linear conversion coefficients as surrogates to unify the RRs by different metric reported in original studies, and thus to avoid uncertainties brought by the conversion of metrics, using a promissory consistent exposure metric or estimating the unit excess RRs in multiple metrics would be highly advocated in future long-term $\mathrm{O}_{3}$-exposure epidemiology studies.

Such linear conversion of risk associations could be validated by Kazemiparkouhi et al. (2020), ${ }^{52}$ where multiple metrics were applied to estimate the mortality risks. For COPD mortality, the RR was 1.072 (95\% CI: $1.067-1.077$ ) by 6mDMA1 for every 10ppbV additional exposure; and after converting into 6mDMA8 metric using the linear coefficient 0.831 (Figure 2), the estimated RR was 1.087 (95\% CI: 1.081-1.093), close to the literature reported 1.084 (95\% CI: 1.079-1.089), ${ }^{52}$ which justified our linear conversion method. Converting Cross-metric linear conversions would not change the risk association direction, but using different exposure metrics when estimating the $\mathrm{O}_{3}$ exposure attributable mortality risks could potentially cause discrepancies. For an instance, Kazemiparkouhi et al. (2020) concluded excess hazards of long-term $\mathrm{O}_{3}$ exposure on all-cause mortality using 6mDMA1 and 6mDMA8 as quantitative metrics, but $6 \mathrm{mDA} 24$ led to a specious prevention effect $(\mathrm{RR}=0.990,95 \% \mathrm{CI}$ : 0.988-0.991), which should be attributed to the existence of a theoretical exposure safety level for $\mathrm{O}_{3}$ below which no negative health effects should occur. Under this circumstance, lower- 
level metrics (e.g. ADA24) by averaging the peak $\mathrm{O}_{3}$ exposures might obscure the effective doses above the threshold, and also reduce the signal-to-noise ratios, so that were of lower credibility in recognising hazardous population exposures than higher-level metrics (e.g. 6mDMA8).

Data mining techniques were able to realise high-accuracy predictions of surface $\mathrm{O}_{3}$ concentrations, but errors were never avoidable. Carey et al. (2013) used a basic IDW spatial interpolation approach to obtain the surface $\mathrm{O}_{3}$ concentrations where the $\mathrm{R}^{2}$ were $0.24-0.76,{ }^{42}$ while years later Di et al. (2018) applied an ensemble learning approach, achieving $\mathrm{R}^{2}=0.80, \mathrm{RMSE}=2.91 \mathrm{ppbV} .{ }^{50}$ Carey et al. (2013) reported the IQR of $\mathrm{O}_{3}$ exposure concentrations as $3.0 \mathrm{ppbV}$, which was comparable to the RMSE of Di et al. (2018). ${ }^{50}$ Besides, lower $\mathrm{R}^{2}$ could be accompanied with higher prediction errors, which might have concealed the highest and lowest quartiles, and led to failures in distinguishing the population-level exposures. This concern had been reflected in our subgroup meta-analysis by exposure metrics, that lower-level metrics were more inclined to report insignificant risks, which also cast sceptics on the reliability of studies covering narrow exposure variabilities. We therefore are in favour of the Lancet suggestions to use peak metrics to quantify the long-term $\mathrm{O}_{3}$ exposure such as 6mDMA8, and also think highly of the state-of-the-art data techniques to reduce errors in $\mathrm{O}_{3}$ concentration prediction, so as to make a distinction between the high- and low-exposure populations.

\subsection{Hierarchical classification of diseases}

The causes of mortalities analysed in our study followed hierarchical subordinate relationships, as the all-cause mortality consisted of cardiovascular diseases, respiratory diseases, cancer and other causes; chronic obstructive pulmonary disease belonged to respiratory category; and ischaemic heart disease, stroke, congestive heart failure and other cerebrovascular diseases all subordinated to cardiovascular symptoms. On this occasion, estimating all $\mathrm{O}_{3}$-exposure induced mortalities could follow a bottom-up scheme by adding up subgroups of diseases. However, for the historical $\mathrm{O}_{3}$-associated mortalities, GBD attributed all $\mathrm{O}_{3}$-associated mortalities onto COPD-induced premature deaths, ${ }^{20}$ which we thought were of spaces for further explorations. Long-term $\mathrm{O}_{3}$ exposure had shown significant association with excess cardiovascular mortalities, and thus we should update the mortality estimations in further studies by including CVD altogether into consideration. 


\subsection{Application of risks}

The widest applications of the estimated risk association strengths were to project how many people would be affected by long-term ambient $\mathrm{O}_{3}$ exposure. For example, Malley et al. (2017) estimated 1.23 (95\% UI: 0.85-1.62) million respiratory deaths attributable to $\mathrm{O}_{3}$ exposure in $2010,{ }^{55}$ using the risk strength by Turner et al. (2016) as HR $=1.12(95 \%$ UI: $1.08-1.16) \cdot{ }^{47}$ This estimation was much higher than the 2019 GBD report: 0.31 (95\% UI: 0.15-0.49) million, as had been highlighted in another recent study, ${ }^{24}$ which should be attributed to the use of high HR value among all included studies. We had also found some other studies using one singular HR value for population risk estimations, ${ }^{17,56-59}$ but we would still encourage further relevant studies consider multi-study pooled RRs, which could effectively reduce potential biases from a single study.

\subsection{Limitations}

According to our literature search, cohort-based $\mathrm{O}_{3}$-health studies were still rather rare, which could be responsible for the relatively large uncertainties in the meta-analysis pooled RRs. Scarcity of credible evidences also restricted the effects of conventional approaches to construct exposure-response curves, and our methodological innovation would require further relevant studies for substantiation. The cross-metric linear conversion factors were estimated relying on observations from available sites, which however might not be sufficiently representative of the global residential areas, as observational sites in India, Africa, and Latin America were still sparse. With everincreasing popularisation of the in situ monitoring networks, the cross-metric conversion factors might need calibration with more comprehensive observations, so that the pooled RRs should also be updated accordingly.

\subsection{Further study suggestions}

We suggest that further environmental epidemiology studies, especially long-term $\mathrm{O}_{3}$ exposure related researches, clearly report i) the methodologies to obtain ambient $\mathrm{O}_{3}$ concentrations, the spatiotemporal resolution, and prediction accuracy of the database; ii) the exposure metrics used for risk estimation; and iii) the statistical distribution of the $\mathrm{O}_{3}$ exposure concentrations. The data-oriented methodologies to accomplish full spatial coverage ambient air $\mathrm{O}_{3}$ concentrations for individual-level exposure assignment should 
be transparent as the construction credibility of air pollution concentration database should also be rigorously assessed, which were the foundation of epidemiological followup studies. We would advocate the report of exposure metrics in future $\mathrm{O}_{3}$-health studies so as to avoid confusions when comparing the risks with literature and conducting metaregression; and empirically, warm-season average (6mDMA8) or daily 8-hour maximum by annual average (ADMA8) were more preferred as epidemiological study metrics. ${ }^{19}$ We also recommend future studies estimate risks with multiple $\mathrm{O}_{3}$ metrics; and describing the statistical distribution of the $\mathrm{O}_{3}$ exposure concentrations are another suggested element to assess the reliability of risk estimation models, and would also be useful in exposure-response tendency exploration.

Our review highlights a deficiency existing in current environmental health research literatures, that studies on long-term $\mathrm{O}_{3}$ exposure health effects are still rather rare compared to particulate matter-based studies. ${ }^{60}$ Also, the meta-analysis results might be geographically-biased, since large-scale $\mathrm{O}_{3}$ exposure health risk studies till 2021 did not cover Asia, Africa or Latin America regions. However, there are some thriving cohorts such as the Multi-Country Multi-City (MCC) Collaborative Research Network covering over 22 countries or regions, ${ }^{61}$ and the China Kadoorie Biobank (CKB) enrolling over 0.5 million people, ${ }^{62}$ working on environmental exposure projects. We are optimistic that more research will come out to fill in the literature gap of multi-region population-based studies.

\section{CONCLUSIONS}

Our state-of-the-science systematic review has summarised cohort studies exploring the associations between long-term ambient $\mathrm{O}_{3}$ exposure and multi-cause mortality risks. Current studies support $\mathrm{O}_{3}$-exposure attributable additional mortalities caused from all causes, respiratory diseases, chronic obstructive pulmonary disease, cardiovascular diseases, and congestive heart failure, but no significant mortality risks are found for ischaemic heart diseases, all-type cerebrovascular diseases, stroke, pneumonia, and lung cancer based on the current evidences. Exposure metrics are crucial for health risk estimations of long-term $\mathrm{O}_{3}$ exposure and meta-analysis to pool the multi-study risks, for which we develop a linear conversion approach to harmonise the different metrics. Further researches on long-term $\mathrm{O}_{3}$ observations and exposure-induced mortalities are encouraged to corroborate or contradict our linear conversion factors and meta-analysis results by providing more solid evidences, so as to strengthen the $\mathrm{O}_{3}$-health literatures. 


\section{Copyright}

The Corresponding Author has the right to grant on behalf of all authors and does grant on behalf of all authors, a worldwide licence to the Publishers and its licensees in perpetuity, in all forms, formats and media (whether known now or created in the future), to i) publish, reproduce, distribute, display and store the Contribution, ii) translate the Contribution into other languages, create adaptations, reprints, include within collections and create summaries, extracts and/or, abstracts of the Contribution, iii) create any other derivative work(s) based on the Contribution, iv) to exploit all subsidiary rights in the Contribution, v) the inclusion of electronic links from the Contribution to third party material where-ever it may be located; and, vi) licence any third party to do any or all of the above.

\section{Competing Interest Statement}

All authors have completed the Unified Competing Interest form and declare: no support from any organisation for the submitted work; no financial relationships with any organisations that might have an interest in the submitted work in the previous three years; and no other relationships or activities that could appear to have influenced the submitted work.

\section{Author Contributions}

ATA and YG conceived the idea for the review; HZS, CL and PY performed the literature search; HZS and PY conducted statistical analyses; HZS, ATA, YG, PY, SH, JM, HS and LY contributed to discussions; HZS wrote the article; and MW scrutinised the languages. HZS is the guarantor who accepted the full responsibility for the finished article, owned full access to all relevant data, and controlled the decision to publish. The two joint corresponding authors, ATA and YG, attests that all listed authors meet authorship criteria and that no others meeting the criteria have been omitted. The guarantor, HZS, affirms that the manuscript is an honest, accurate, and transparent account of the study being reported, and no important aspects of the study have been omitted. No ethical approval is needed for a systematic review and meta-analysis. 


\section{Funding Acknowledgement}

This study is funded by UK Natural Environment Research Council (NERC), UK National Centre for Atmospheric Science (NCAS), Australian Research Council (DP210102076) and Australian National Health and Medical Research Council (APP2000581). HZS, MW, and SH receive funding from Engineering and Physical Sciences Research Council (EPSRC) via the UK Research and Innovation (UKRI) Centre for Doctoral Training in Application of Artificial Intelligence to the study of Environmental Risks (AI4ER, EP/S022961/1). ATA acknowledges funding from NERC (NE/P016383/1) and through the Met Office UKRI Clean Air Programme. YG is supported by a Career Development Fellowship of the Australian National Health and Medical Research Council (APP1163693). All contents in this study are solely the responsibility of the grantees and do not represent the official views of the supporting agencies.

\section{Data Availability}

The surface $\mathrm{O}_{3}$ observations are archived in the Tropospheric Ozone Assessment Report (TOAR, https://b2share.fz-juelich.de/communities/TOAR) repository and China National Environmental Monitoring Centre (CNEMC, http://www.cnemc.cn/en/) repository, which are accessible to the public. The cohort-based long-term $\mathrm{O}_{3}$ exposureassociated cause-specific mortality risks are all available in the main text or supplementary materials of the selected studies.

\section{Supplementary Information}

Further detailed information can be found in the Supplementary Materials (PDF) consisting of 17 pages with 6 sections of texts as "imputation procedures for exposure distribution" (S1), "enhanced integrated exposure-response curve-fitting" (S2), "demonstrative procedures of enhanced exposure-response trend curve-fitting" (S3), "undefined metric imputation" (S4), "interpretation and procedure of cross-metric linear conversion" (S5), and "detailed study assessment" (S6), as well as 6 tables and 7 figures to strengthen the results and discussions presented in the main text. A PRISMA Checklist (PDF) was provided to verify the integrity of this study. 


\section{TABLES}

\section{Table 1 Summary of cohort characteristics included for meta-analysis.}

\begin{tabular}{|c|c|c|c|c|c|c|c|c|c|}
\hline Study & Cohort & Country & $\begin{array}{l}\text { Follow-up } \\
\text { Duration }\end{array}$ & $\begin{array}{l}\text { Population } \\
\text { Type }\end{array}$ & $\begin{array}{l}\text { Sample } \\
\text { Size }\end{array}$ & Sex & Age & Key Confounding Adjustment & Mortality Causes \\
\hline Abbey et al. $1999^{35}$ & AHSMOG & USA & 1977-1992 & Occupational & 6,182 & FM & $27-95$ & $\begin{array}{c}\text { age, sex, BMI, smoking, individual } \\
\text { demographic features } \| \text {, lifestyle features }^{\perp}, \\
\text { medical history }\end{array}$ & AC, RESP, LC \\
\hline Lipfert et al. $2006^{36}$ & WU-EPRI & USA & $1976-1996$ & General & 90,070 & M & $\begin{array}{c}51.2 \\
(12.0)^{\S}\end{array}$ & $\begin{array}{l}\text { age, ethnicity, BMI, smoking, traffic density, } \\
\qquad \mathrm{NO}_{2}, \mathrm{CO}\end{array}$ & $\mathrm{AC}$ \\
\hline Jerrett et al. $2009^{37}$ & ACS CPS II & USA & $1977-2000$ & General & 448,850 & FM & 56.6 & \multirow{3}{*}{$\begin{array}{l}\text { age, sex, ethnicity, BMI, smoking, individual } \\
\text { demographic features, lifestyle features, } \mathrm{PM}_{2.5}\end{array}$} & AC, RESP, CVD, IHD \\
\hline Krewski et al. $2009^{38}$ & ACS CPS II & USA & $1982-2000$ & General & 531,185 & FM & $\geq 30$ & & AC, IHD, LC \\
\hline Smith et al. $2009^{39}$ & ACS CPS II & USA & $1982-2000$ & General & 352,242 & FM & 56.6 & & AC, RESP, CVD \\
\hline Lipsett et al. $2011^{40}$ & CTS & USA & $1998-2005$ & Occupational & 124,614 & $\mathrm{~F}$ & $\geq 20$ & $\begin{array}{l}\text { age, ethnicity, BMI, smoking, lifestyle } \\
\text { features, medical treatment }\end{array}$ & $\begin{array}{l}\text { AC, RESP, CVD, IHD, } \\
\text { stroke, CEVD, LC }\end{array}$ \\
\hline $\begin{array}{l}\text { Zanobetti } \\
\text { et al. } 2011^{41}\end{array}$ & Medicare & USA & $1985-2006$ & General & $3,210,511$ & FM & $\geq 65$ & age, sex, ethnicity, medical history & COPD \\
\hline Carey et al. $2013^{42}$ & CPRD & UK & 2003-2007 & General & 824,654 & FM & $40-89$ & $\begin{array}{l}\text { age, sex, BMI, smoking, individual } \\
\text { demographic features }\end{array}$ & AC, RESP, LC \\
\hline Jerrett et al. $2013^{43}$ & ACS CPS II & USA & $1982-2000$ & General & 73,711 & FM & $\begin{array}{c}57.4 \\
(10.6)\end{array}$ & $\begin{array}{l}\text { age, sex, smoking, individual demographic } \\
\text { features, lifestyle features }\end{array}$ & $\begin{array}{l}\text { AC, RESP, CVD, IHD, } \\
\text { stroke, LC }\end{array}$ \\
\hline Bentayeb et al. $2015^{44}$ & GAZEL & France & $1989-2013$ & Occupational & 20,327 & FM & $\begin{array}{l}43.7 \\
(3.5)\end{array}$ & $\begin{array}{l}\text { age, sex, BMI, smoking, individual } \\
\text { demographic features, lifestyle features }\end{array}$ & AC, RESP, CVD \\
\hline Crouse et al. $2015^{45}$ & CANCHEC & Canada & 1991-2006 & General & $2,521,525$ & FM & $\geq 25$ & $\begin{array}{l}\text { age, sex, individual and area-level } \\
\text { demographic features, } \mathrm{PM}_{2.5}, \mathrm{NO}_{2}\end{array}$ & $\begin{array}{l}\text { AC, RESP, COPD, CVD, } \\
\text { IHD, CEVD, LC }\end{array}$ \\
\hline Tonne et al. $2016^{46}$ & MINAP & UK & 2003-2010 & General & 18,138 & FM & $\begin{array}{c}68 \\
(14)\end{array}$ & $\begin{array}{l}\text { age, sex, ethnicity, smoking, medical history, } \\
\text { area-level demographic features }\end{array}$ & $\mathrm{AC}$ \\
\hline Turner et al. $2016^{47}$ & ACS CPS II & USA & $1982-2004$ & General & 669,046 & FM & $\geq 30$ & $\begin{array}{l}\text { age, sex, BMI, smoking, individual and area- } \\
\text { level demographic features, } \mathrm{PM}_{2.5}, \mathrm{NO}_{2}\end{array}$ & $\begin{array}{l}\text { AC, RESP, COPD, CVD, } \\
\text { IHD, CEVD, pneumonia }\end{array}$ \\
\hline $\begin{array}{l}\text { Weichenthal } \\
\text { et al. } 2017^{48}\end{array}$ & CANCHEC & Canada & 2001-2011 & General & $2,448,500$ & FM & $25-89$ & $\begin{array}{l}\text { age, sex, ethnicity, individual and area-level } \\
\text { demographic features }\end{array}$ & AC, RESP, CVD \\
\hline Cakmak et al. $2018^{49}$ & CANCHEC & Canada & 1991-2011 & General & $2,291,250$ & FM & $\geq 25$ & $\begin{array}{l}\text { age, sex, individual demographic features, } \\
\qquad \mathrm{PM}_{2.5}\end{array}$ & AC, COPD, IHD, LC \\
\hline Di et al. $2018^{50}$ & Medicare & USA & 2000-2012 & General & $60,925,443$ & FM & $\geq 65$ & $\begin{array}{l}\text { age, sex, ethnicity, BMI, smoking, individual } \\
\text { and area-level demographic features, } \\
\text { meteorological features, } \mathrm{PM}_{2.5}\end{array}$ & $\mathrm{AC}$ \\
\hline $\begin{array}{l}\text { Hvidtfeldt } \\
\text { et al. } 2019^{51}\end{array}$ & $\mathrm{DDCH}$ & Denmark & 1993-1997 & General & 49,596 & FM & $50-64$ & $\begin{array}{l}\text { age, sex, BMI, smoking, individual and area- } \\
\text { level demographic features, noise }\end{array}$ & AC, RESP, CVD \\
\hline $\begin{array}{l}\text { Kazemiparkouhi } \\
\text { et al. } 2019^{52}\end{array}$ & Medicare & USA & $2000-2008$ & General & $22,159,190$ & FM & $\geq 65$ & $\begin{array}{c}\text { age, sex, ethnicity, area-level demographic } \\
\text { features, } \mathrm{PM}_{2.5}\end{array}$ & $\begin{array}{l}\text { AC, RESP, COPD, CVD, } \\
\text { IHD, CEVD, LC, } \\
\text { pneumonia }\end{array}$ \\
\hline Lim et al. $2019^{53}$ & NIH-AARP & USA & $1995-2011$ & General & 548,780 & FM & $50-71$ & $\begin{array}{c}\text { age, sex, ethnicity, BMI, smoking, individual } \\
\text { demographic features, } \mathrm{PM}_{2.5}, \mathrm{NO}_{2} \text {, daily } \\
\text { maximum temperature }\end{array}$ & $\begin{array}{l}\text { AC, RESP, COPD, CVD, } \\
\text { IHD, CEVD, LC, } \\
\text { pneumonia }\end{array}$ \\
\hline Paul et al. $2020^{54}$ & ONPHEC & Canada & $1996-2015$ & Diabetes & 452,590 & FM & $35-85$ & age, sex, area-level demographic features & CVD \\
\hline $\begin{array}{l}\text { Cohort abbre } \\
\text { Cancer Preve } \\
\text { Health and E } \\
\text { American Ass } \\
\| \text { Demograph } \\
\text { and residence } \\
\text { demographic } \\
\perp \text { Lifestyle fe } \\
\text { various comb }\end{array}$ & $\begin{array}{l}\text { viations: AHSM } \\
\text { ntion Study; CT } \\
\text { nvironment Coh } \\
\text { ociation of Ret } \\
\text { ic features inclu } \\
\text { location (urban } \\
\text { features. } \\
\text { atures included } \\
\text { inations of lifes }\end{array}$ & $\begin{array}{l}\text { IOG, Adventi } \\
\text { S, Californic } \\
\text { iort; MINAP } \\
\text { red Persons; } \\
\text { ded marital s } \\
\text { or rural), in } \\
\text { consumption } \\
\text { tyle features. }\end{array}$ & $\begin{array}{l}\text { st Health Stu } \\
\text { Teacher Stu } \\
\text { National Au } \\
\text { ONPHEC, } \\
\text { tatus, educati } \\
\text { come level an } \\
\text { s of alcohol, }\end{array}$ & $\begin{array}{l}\text { y of Smog; WU } \\
\text { ly; CPRD, Clini } \\
\text { lit of Myocardia } \\
\text { itario Populatio } \\
\text { on attainment, en } \\
\text { d socioeconomic } \\
\text { ietary fat, veget }\end{array}$ & $\begin{array}{l}\text { PRI, Washing } \\
\text { l Practice Res } \\
\text { Infarction Pro } \\
\text { Health and E } \\
\text { loyment statu } \\
\text { tatus (SES), a } \\
\text { les and fruits }\end{array}$ & $\begin{array}{l}c t \text {; } \\
\text { virot } \\
\text { and }\end{array}$ & $\begin{array}{l}\text { versity-E } \\
\text { atalink; } \\
\text { CH, Dar } \\
\text { ent Coho } \\
\text { cupation } \\
\text { nal popu } \\
\text { fibre), a }\end{array}$ & $\begin{array}{l}\text { lectric Power Research Institute; ACS CPS, Americ } \\
\text { GAZEL, GAZ de France and ÉLectricité; CANCHE } \\
\text { iish Diet, Cancer and Health; NIH-AARP, National } \\
\text { rt. } \\
\text { lal class, aboriginal ancestry, visible minority ethnici } \\
\text { lation density. Different studies adjusted various con } \\
\text { at vitamins, and physical activity frequency. Differe }\end{array}$ & $\begin{array}{l}\text { Cancer Society } \\
\text { Canadian Census } \\
\text { istitute of Health, } \\
\text { es, immigrant status } \\
\text { inations of } \\
\text { studies adjusted }\end{array}$ \\
\hline
\end{tabular}


Table 2 Data sources and statistical methods of $\mathrm{O}_{3}$ exposure assignment. Methodological ratings were based on spatial interpolation and multi-data assimilation approaches. Spatial resolutions, exposure metrics, and levels of incremental risk ratio were also listed.

\begin{tabular}{|c|c|c|c|c|c|c|}
\hline Study & Data Sources & Methods & Resolution & Rating & Metrics & $\begin{array}{c}\text { Level of } \\
\text { incremental } \\
\text { risk ratio }\end{array}$ \\
\hline Abbey et al. $1999^{35}$ & monitoring station observations & IDW interpolation & NR & Low & ADMA8 & $12.03 \mathrm{ppbV}$ \\
\hline Lipfert et al. $2006^{36}$ & monitoring station observations & $\begin{array}{l}\text { nearest matching } \\
\quad \text { (assumed) }{ }^{\dagger}\end{array}$ & NR & Low & ADMA1 & $40 \mathrm{ppbV}$ \\
\hline Jerrett et al. $2009^{37}$ & monitoring station observations & $\begin{array}{l}\text { nearest matching } \\
\quad \text { (assumed) }\end{array}$ & NR & Low & 6mDMA1 & $10 \mathrm{ppbV}$ \\
\hline Krewski et al. $2009^{38}$ & monitoring station observations & $\begin{array}{l}\text { ordinary kriging } \\
\text { interpolation }\end{array}$ & NR & Low & 6mDMA1 & $10 \mathrm{ppbV}$ \\
\hline Smith et al. $2009^{39}$ & monitoring station observations & $\begin{array}{l}\text { nearest matching } \\
\quad \text { (assumed) }\end{array}$ & NR & Low & 6mDMA1 & $1 \mu \mathrm{g} / \mathrm{m}^{3}$ \\
\hline Lipsett et al. $2011^{40}$ & monitoring station observations & IDW interpolation & $250 \mathrm{~m}$ & Low & ADA24 & $22.96 \mathrm{ppbV}$ \\
\hline $\begin{array}{l}\text { Zanobetti } \\
\text { et al. } 2011^{41}\end{array}$ & monitoring station observations & $\begin{array}{l}\text { nearest matching } \\
\quad \text { (assumed) }\end{array}$ & NR & Low & 6mDMA8 & $5 \mathrm{ppbV}$ \\
\hline Carey et al. $2013^{42}$ & monitoring station observations & $\begin{array}{l}\text { interpolation } \\
\text { (IDW assumed) }\end{array}$ & $1 \mathrm{~km}$ & Low & $\mathrm{ADA} 24$ & $3.0 \mu \mathrm{g} / \mathrm{m}^{3}$ \\
\hline Jerrett et al. $2013^{43}$ & monitoring station observations & IDW interpolation & NR & Low & $\mathrm{ADA} 24$ & $\begin{array}{c}24.1782 \\
\text { ppbV }\end{array}$ \\
\hline Bentayeb et al. $2015^{44}$ & $\begin{array}{l}\text { monitoring station observations, model } \\
\text { simulation, other auxiliary predictors }\end{array}$ & $\begin{array}{l}\text { universal kriging } \\
\text { interpolation }\end{array}$ & $2 \mathrm{~km}$ & Moderate & 6mDMA8 & $12.3 \mu \mathrm{g} / \mathrm{m}^{3}$ \\
\hline Crouse et al. $2015^{45}$ & $\begin{array}{l}\text { monitoring station observations, model } \\
\text { simulation }\end{array}$ & linear data assimilation & $21 \mathrm{~km}$ & Good & 6mDMA8 & $9.5 \mathrm{ppbV}$ \\
\hline Tonne et al. $2016^{46}$ & KCLurban air dispersion model simulation & NR & $20 \mathrm{~m}$ & Moderate & $\mathrm{ADA} 24$ & $5.3 \mu \mathrm{g} / \mathrm{m}^{3}$ \\
\hline Turner et al. $2016^{47}$ & $\begin{array}{c}\text { monitoring station observations, CMAQ model } \\
\text { simulation }\end{array}$ & $\begin{array}{l}\text { hierarchical Bayesian } \\
\text { space-time data } \\
\text { assimilation }\end{array}$ & $12 \mathrm{~km}$ & High & $\begin{array}{l}\text { ADMA8 } \\
6 \text { mDMA8 }\end{array}$ & $10 \mathrm{ppbV}$ \\
\hline $\begin{array}{l}\text { Weichenthal } \\
\text { et al. } 2017^{48}\end{array}$ & $\begin{array}{l}\text { monitoring station observations, model } \\
\text { simulation }\end{array}$ & linear data assimilation & $21 \mathrm{~km}$ & Good & $6 \mathrm{mDMA} 8$ & $10.503 \mathrm{ppbV}$ \\
\hline Cakmak et al. $2018^{49}$ & $\begin{array}{l}\text { monitoring station observations, model } \\
\text { simulation }\end{array}$ & linear data assimilation & $21 \mathrm{~km}$ & Good & 6mDMA8 & $10 \mathrm{ppbV}$ \\
\hline Di et al. $2018^{50}$ & $\begin{array}{l}\text { monitoring station observations, model } \\
\text { simulation, satellite remote sensing } \\
\text { observations, other auxiliary predictors }\end{array}$ & $\begin{array}{l}\text { ensemble machine } \\
\text { learning }\end{array}$ & $1 \mathrm{~km}$ & High & $6 \mathrm{mDA} 24$ & $10 \mathrm{ppbV}$ \\
\hline $\begin{array}{l}\text { Hvidtfeldt } \\
\text { et al. } 2019^{51}\end{array}$ & AirGIS dispersion model simulation & NR & $1 \mathrm{~km}$ & Moderate & ADA24 & $10 \mu \mathrm{g} / \mathrm{m}^{3}$ \\
\hline $\begin{array}{l}\text { Kazemiparkouhi } \\
\text { et al. } 2019^{52}\end{array}$ & monitoring station observations & $\begin{array}{l}\text { nearest matching } \\
\quad \text { (assumed) }\end{array}$ & $6 \mathrm{~km}$ & Low & $\begin{array}{l}\text { 6mDMA1 } \\
6 \mathrm{mDMA} 8 \\
6 \mathrm{mDA} 24\end{array}$ & $10 \mathrm{ppbV}$ \\
\hline Lim et al. $2019^{53}$ & $\begin{array}{c}\text { monitoring station observations, CMAQ model } \\
\text { simulation }\end{array}$ & $\begin{array}{l}\text { Bayesian space-time } \\
\text { downscaling }\end{array}$ & $12 \mathrm{~km}$ & High & 6mDMA8 & $10 \mathrm{ppbV}$ \\
\hline Paul et al. $2020^{54}$ & $\begin{array}{l}\text { monitoring station observations, model } \\
\text { simulation }\end{array}$ & linear data assimilation & $21 \mathrm{~km}$ & Good & 6mDMA8 & $6.4 \mathrm{ppbV}$ \\
\hline
\end{tabular}


Table 3 Pooled RRs for long-term 10-ppbV incremental $O_{3}$-exposure attributable multi-cause mortalities by 4 most widely used metrics and unit unified crude risks without metric harmonisation.

\begin{tabular}{|c|c|c|c|c|c|}
\hline Mortality causes & 6mDMA8 & 6mDA24 & ADMA8 & ADA24 & Crude \\
\hline All causes & $1.010(1.005,1.015)$ & $1.016(1.009,1.025)$ & $1.011(1.006,1.017)$ & $1.019(1.010,1.029)$ & $1.011(1.005-1.017)$ \\
\hline Respiratory diseases & $1.027(1.004,1.049)$ & $1.046(1.007,1.085)$ & $1.031(1.005,1.057)$ & $1.054(1.009,1.100)$ & $1.034(1.010-1.059)$ \\
\hline Chronic obstructive pulmonary disease & $1.061(1.006,1.119)$ & $1.106(1.010,1.211)$ & $1.071(1.007,1.139)$ & $1.125(1.012,1.250)$ & $1.060(1.010-1.113)$ \\
\hline Cardiovascular diseases & $1.028(1.001,1.058)$ & $1.049(1.001,1.100)$ & $1.033(1.001,1.067)$ & $1.057(1.002,1.118)$ & $1.039(1.007-1.073)$ \\
\hline Ischaemic heart disease & $1.023(0.992,1.055)$ & $1.040(0.987,1.096)$ & $1.027(0.991,1.064)$ & $1.047(0.985,1.112)$ & $1.027(0.995-1.061)$ \\
\hline Congestive heart failure & $1.102(1.046,1.162)$ & $1.180(1.079,1.290)$ & $1.119(1.053,1.189)$ & $1.213(1.093,1.346)$ & $1.104(1.042-1.170)$ \\
\hline Cerebrovascular diseases & $0.997(0.973,1.020)$ & $0.994(0.955,1.034)$ & $0.996(0.969,1.023)$ & $0.993(0.947,1.040)$ & $0.997(0.970-1.024)$ \\
\hline Lung cancer & $0.984(0.961,1.008)$ & $0.974(0.934,1.013)$ & $0.982(0.955,1.009)$ & $0.969(0.924,1.015)$ & $0.982(0.958-1.002)$ \\
\hline
\end{tabular}




\section{FIGURES}

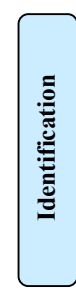

Records identified from searching, among which 70 from MEDLINE, 93 from

EMBASE, and 145 from Web of Science $(n=308)$

Additional literatures identified from 2 other systematic reviews $(n=34)$

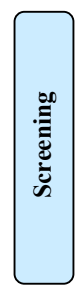

95 records censored due to duplication $(n=247)$
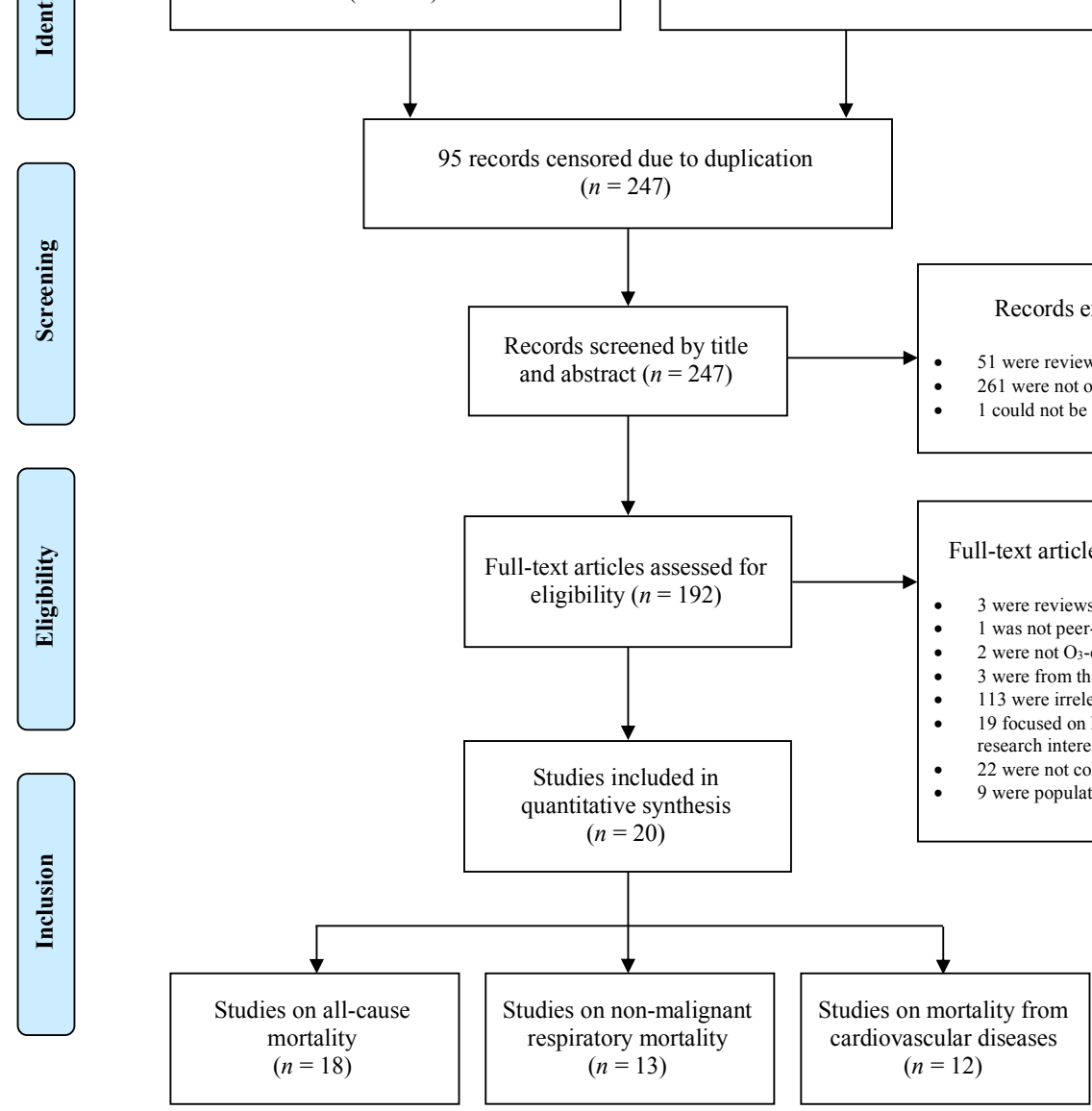

Figure 1 Schematic flowchart of study assessment and selection processes for literature review and meta-analysis. 
medRxiv preprint doi: https://doi.org/10.1101/2021.12.02.21267196; this version posted December 5, 2021. The copyright holder for this preprint (which was not certified by peer review) is the author/funder, who has granted medRxiv a license to display the preprint in perpetuity.

It is made available under a CC-BY-NC-ND 4.0 International license .

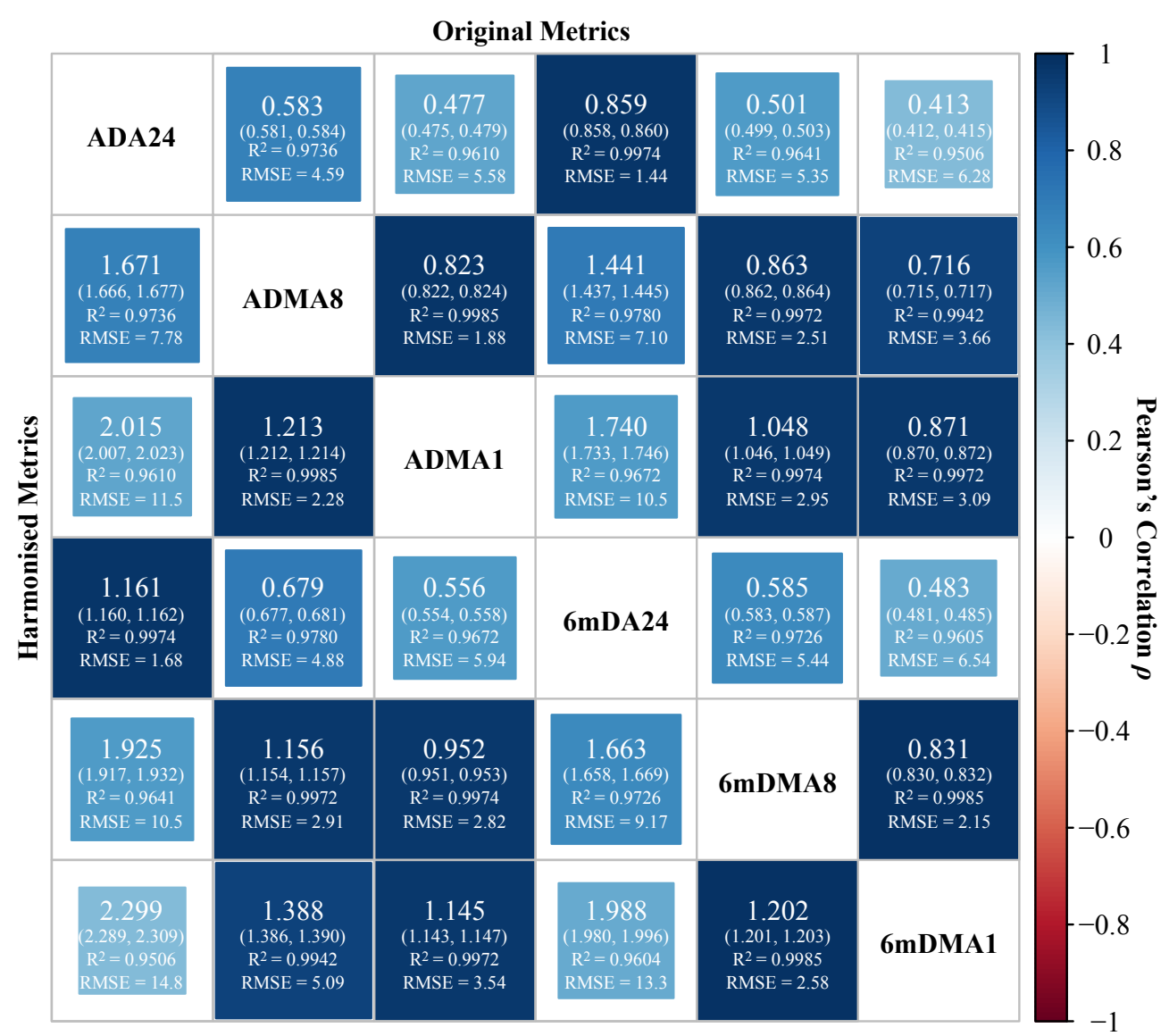

Figure 2 Cross-metric linear relationships and conversion accuracies. The crossmetric linear relationships were scaled by Pearson's correlation coefficients. The crossmetric conversion factors with $95 \%$ confidence intervals $(95 \% \mathrm{CI})$ were estimated by non-intercept linear regression models, accompanied with fitting accuracies quantified by coefficient of determination $\left(\mathrm{R}^{2}\right)$ and root mean square error (RMSE) in ppbV. The conversion factors were defined as multiples from the original metric by column into the target harmonised metric by row, e.g. ADMA8 $=1.671$ ADA24, $\mathrm{R}^{2}=0.9736, \mathrm{RMSE}=$ $7.78 \mathrm{ppbV}$. 


\section{Study}

Abbey et al. 1999 (male cohort) Abbey et al. 1999 (female cohort) Lipfert et al. 2006

Jerrett et al. 2009

Krewski et al. 2009

Smith et al. 2009

Lipsett et al. 2011

Carey et al. 2013

Jerrett et al. 2013

Bentayeb et al. 2015

Crouse et al. 2015

Tonne et al. 2016

Turner et al. 2016

Weichenthal et al. 2017

Cakmak et al. 2018

Di et al. 2018

Hvidtfeldt et al. 2019

Kazemiparkouhi et al. 2019

Lim et al. 2019

Random effects model

Heterogeneity: $I^{2}=94 \%, \tau^{2}<0.0001, p<0.01$
Risk Ratio

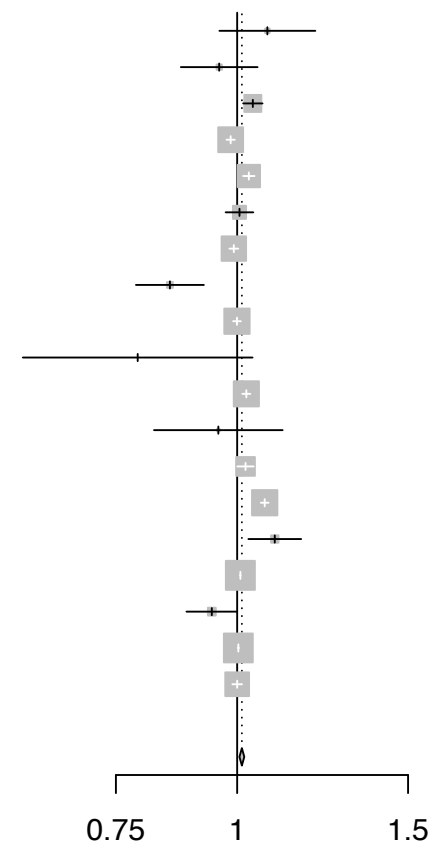

RR $\quad 95 \% \mathrm{Cl}$ Weight

$1.06[0.97,1.17] \quad 0.3 \%$

$0.97[0.89,1.04] \quad 0.4 \%$

$1.03[1.01,1.05] \quad 4.2 \%$

$0.98[0.98,0.99] \quad 9.0 \%$

$1.03[1.01,1.04] \quad 7.3 \%$

$1.01[0.97,1.04] \quad 2.5 \%$

$0.99[0.98,1.00] \quad 8.7 \%$

$0.87[0.82,0.93] \quad 0.5 \%$

$1.00[0.99,1.01] \quad 9.3 \%$

$0.82[0.64,1.03] \quad 0.0 \%$

$1.02[1.01,1.03] \quad 9.2 \%$

$0.97[0.84,1.09] \quad 0.1 \%$

$1.02[1.00,1.04] \quad 5.1 \%$

$1.06[1.05,1.07] \quad 9.3 \%$

$1.08[1.03,1.14] \quad 0.8 \%$

$1.01[1.01,1.01] \quad 12.2 \%$

$0.95[0.90,1.00] \quad 0.9 \%$

$1.00[1.00,1.00] 12.1 \%$

$1.00[0.99,1.01] \quad 8.2 \%$

$1.01[1.01,1.02] 100.0 \%$ 1.5

Figure 3 Pooled estimates of all-cause mortality risk associated with every 10 -ppbV incremental $\mathrm{O}_{3}$ exposure by $6 \mathrm{mDMA8}$ metric. 


\section{Respiratory Diseases}

\section{Study}

Abbey et al. 1999 (male cohort) Abbey et al. 1999 (female cohort) Jerrett et al. 2009

Smith et al. 2009

Lipsett et al. 2011

Carey et al. 2013

Jerrett et al. 2013

Bentayeb et al. 2015

Crouse et al. 2015

Turner et al. 2016

Weichenthal et al. 2017

Hvidtfeldt et al. 2019

Kazemiparkouhi et al. 2019

Lim et al. 2019

Random effects model

Heterogeneity: $I^{2}=83 \%, \tau^{2}=0.0013, p<0.01$

\section{Chronic Obstructive Pulmonary Disease}

Study

Zanobetti et al. 2011

Crouse et al. 2015

Turner et al. 2016

Cakmak et al. 2018

Kazemiparkouhi et al. 2019

Lim et al. 2019

Random effects model

Heterogeneity: $I^{2}=95 \%, \tau^{2}=0.0052, p<0.01$
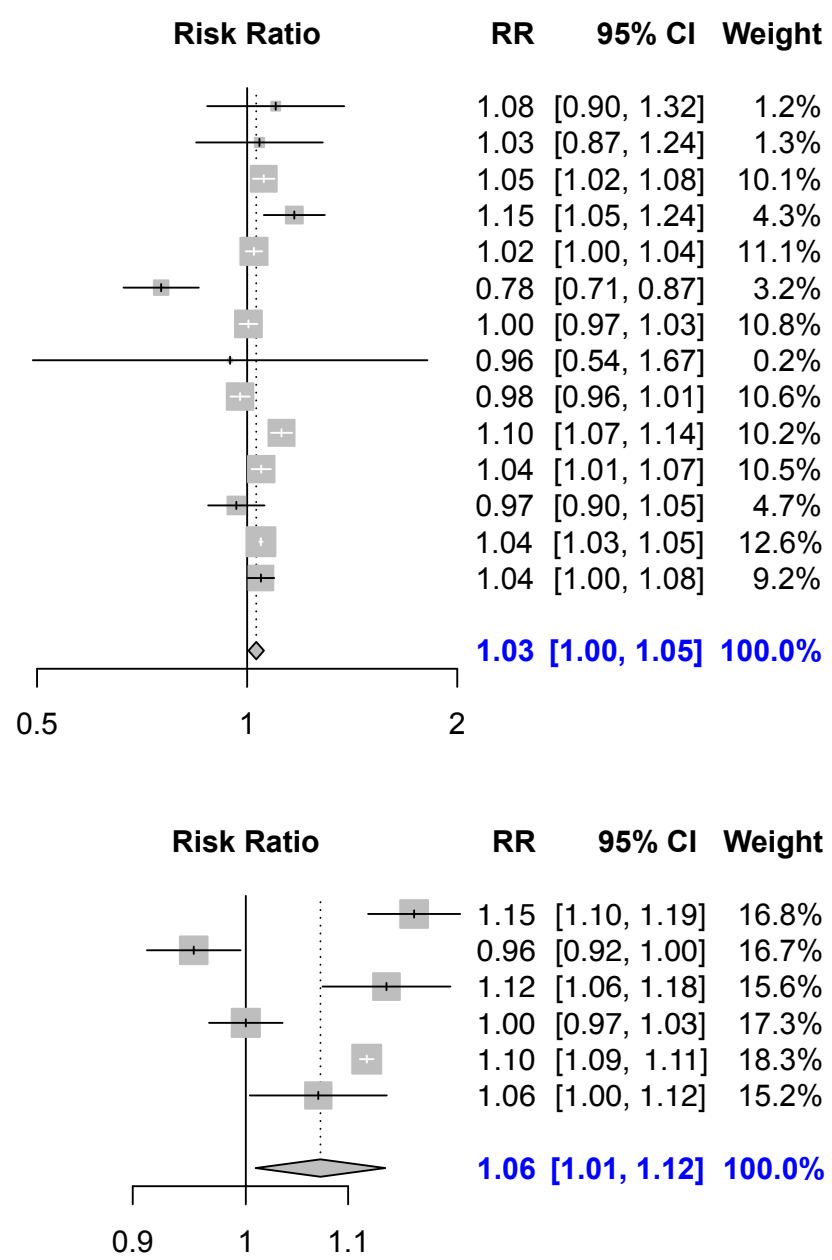

Figure 4 Pooled estimates of respiratory diseases and COPD mortality risks associated with every $10-p p b V$ incremental $O_{3}$ exposure by 6 mDMA8 metric. 


\section{Cardiovascular Diseases}

\section{Study}

Jerrett et al. 2009

Smith et al. 2009

Lipsett et al. 2011

Jerrett et al. 2013

Bentayeb et al. 2015

Crouse et al. 2015

Turner et al. 2016

Weichenthal et al. 2017

Hvidtfeldt et al. 2019

Kazemiparkouhi et al. 2019

Lim et al. 2019

Paul et al. 2020

Random effects model

Heterogeneity: $I^{2}=98 \%, \tau^{2}=0.0023, p<0.01$

Congestive Heart Failure

Study

Zanobetti et al. 2011

Turner et al. 2016

Kazemiparkouhi et al. 2019

Lim et al. 2019

Random effects model

Heterogeneity: $I^{2}=91 \%, \tau^{2}=0.0035, p<0.01$
Risk Ratio

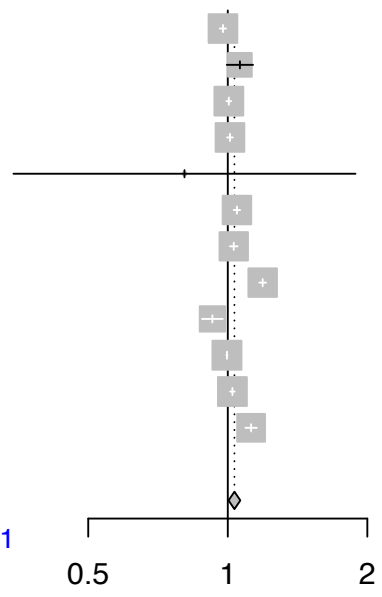

RR $\quad 95 \%$ Cl Weight

$0.98[0.97,0.99] \quad 9.6 \%$

$1.05[0.99,1.11] \quad 6.6 \%$

$1.01[0.99,1.02] \quad 9.7 \%$

$1.01[1.00,1.03] \quad 9.6 \%$

$0.83[0.39,1.73] \quad 0.1 \%$

$1.04[1.03,1.05] \quad 9.5 \%$

$1.03[1.01,1.04] \quad 9.4 \%$

$1.16[1.15,1.18] \quad 9.5 \%$

$0.94[0.90,0.98] \quad 7.5 \%$

$1.00[0.99,1.00] \quad 9.8 \%$

$1.02[1.01,1.03] \quad 9.7 \%$

$1.10[1.08,1.14] \quad 9.0 \%$

$1.03[1.00,1.06] 100.0 \%$

Figure 5 Pooled estimates of cardiovascular diseases and congestive heart failure mortality risk associated with every $10-p p b V$ incremental $\mathrm{O}_{3}$ exposure by $6 \mathrm{mDMA8}$ metric. 


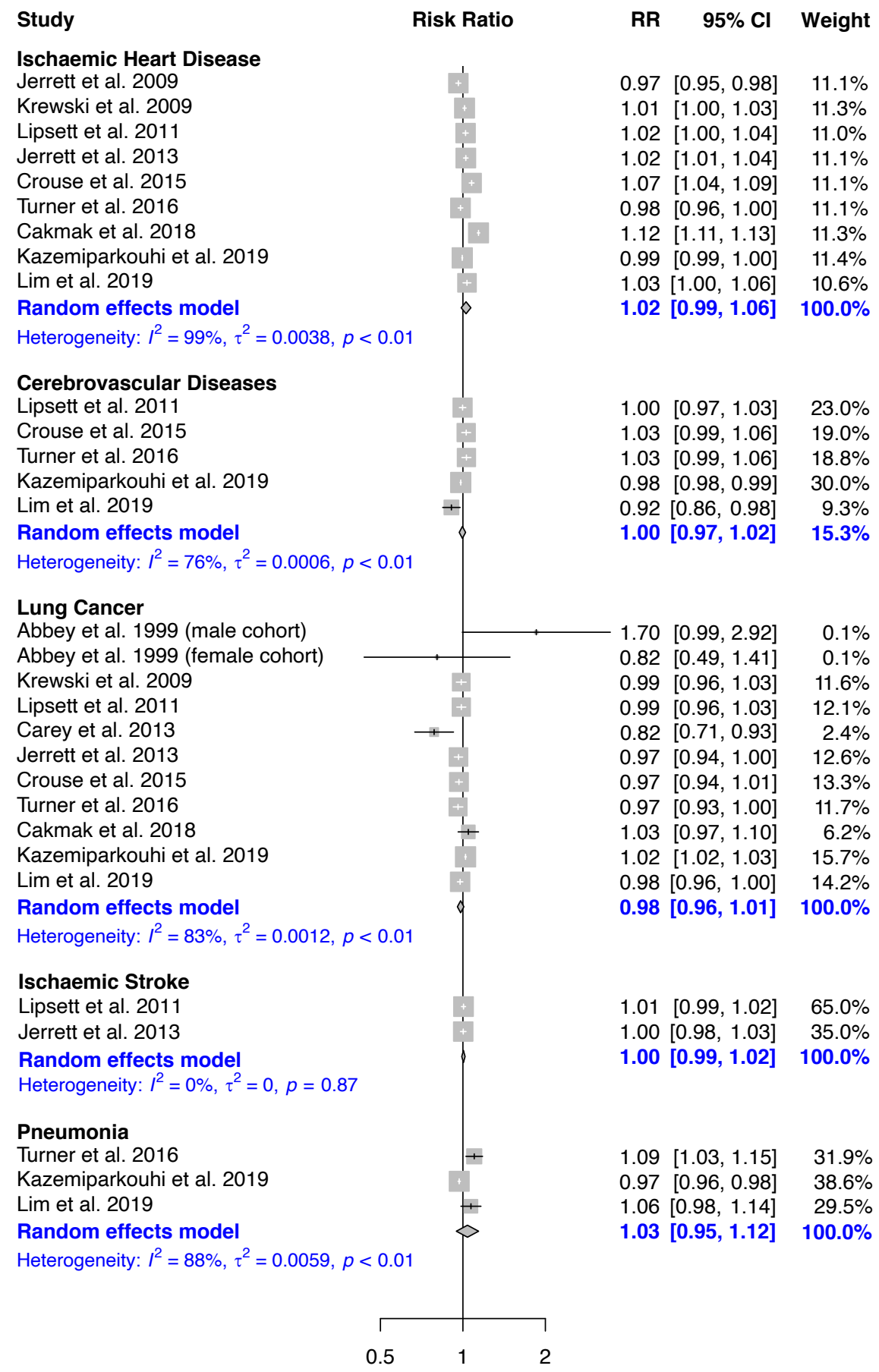

Figure 6 Pooled estimates of ischaemic heart disease, cerebrovascular diseases, lung cancer, ischaemic stroke, and pneumonia mortality risks associated with every 10$\mathrm{ppbV}$ incremental $\mathrm{O}_{3}$ exposure by $6 \mathrm{mDMA8}$ metric. 


\section{REFERENCES}

1. Fu, B.; Gasser, T.; Li, B.; Tao, S.; Ciais, P.; Piao, S.; Balkanski, Y.; Li, W.; Yin, T.; Han, L., Short-lived climate forcers have long-term climate impacts via the carbon-climate feedback. Nat Clim Change 2020, 10, (9), 851-855.

2. Wilson, S. R.; Madronich, S.; Longstreth, J. D.; Solomon, K. R., Interactive effects of changing stratospheric ozone and climate on tropospheric composition and air quality, and the consequences for human and ecosystem health. Photochem Photobiol Sci 2019, 18, (3), 775-803.

3. Stolarski, R. S., The Antarctic ozone hole. Scientific American 1988, 258, (1), 30-37.

4. Ghude, S. D.; Jena, C.; Chate, D. M.; Beig, G.; Pfister, G. G.; Kumar, R.; Ramanathan, V., Reductions in India's crop yield due to ozone. Geophys Res Lett 2014, 41, (15), 5685-5691.

5. Zhang, F.; Zhang, H.; Wu, C.; Zhang, M.; Feng, H.; Li, D.; Zhu, W., Acute effects of ambient air pollution on clinic visits of college students for upper respiratory tract infection in Wuhan, China. Environ Sci Pollut Res Int 2021, 1-11.

6. Zheng, X.-Y.; Orellano, P.; Lin, H.-L.; Jiang, M.; Guan, W.-J., Short-term exposure to ozone, nitrogen dioxide, and sulphur dioxide and emergency department visits and hospital admissions due to asthma: A systematic review and meta-analysis. Environ Int 2021, 150, 106435.

7. Liu, Y.; Pan, J.; Fan, C.; Xu, R.; Wang, Y.; Xu, C.; Xie, S.; Zhang, H.; Cui, X.; Peng, Z.; Shi, C.; Zhang, Y.; Sun, H.; Zhou, Y.; Zhang, L., Short-Term Exposure to Ambient Air Pollution and Mortality From Myocardial Infarction. J Am Coll Cardiol 2021, 77, (3), 271-281.

8. Zhao, R.; Chen, S.; Wang, W.; Huang, J.; Wang, K.; Liu, L.; Wei, S., The impact of short-term exposure to air pollutants on the onset of out-of-hospital cardiac arrest: A systematic review and meta-analysis. Int J Cardiol 2017, 226, 110-117.

9. Han, C.; Lu, Y.; Cheng, H.; Wang, C.; Chan, P., The impact of long-term exposure to ambient air pollution and second-hand smoke on the onset of Parkinson disease: a review and meta-analysis. Public Health 2020, 179, 100110 .

10. Li, J.; Huang, J.; Cao, R.; Yin, P.; Wang, L.; Liu, Y.; Pan, X.; Li, G.; Zhou, M., The association between ozone and years of life lost from stroke, 2013-2017: A retrospective regression analysis in 48 major Chinese cities. J Hazard Mater 2021, 405, 124220.

11. Liu, G.; Sun, B.; Yu, L.; Chen, J.; Han, B.; Li, Y.; Chen, J., The Gender-Based Differences in Vulnerability to Ambient Air Pollution and Cerebrovascular Disease Mortality: Evidences Based on 26781 Deaths. Glob Heart 2020, 15, (1), 46 .

12. Sun, Z.; Yang, L.; Bai, X.; Du, W.; Shen, G.; Fei, J.; Wang, Y.; Chen, A.; Chen, Y.; Zhao, M., Maternal ambient air pollution exposure with spatial-temporal variations and preterm birth risk assessment during 2013-2017 in Zhejiang Province, China. Environ Int 2019, 133, (Pt B), 105242.

13. Global Burden of Disease Collaborative Network, Global Burden of Disease Study 2019 (GBD 2019) Results. In Institute for Health Metrics and Evaluation (IHME): Seattle, United States, 2020.

14. Niu, Z.; Liu, F.; Yu, H.; Wu, S.; Xiang, H., Association between exposure to ambient air pollution and hospital admission, incidence, and mortality of stroke: an updated systematic review and meta-analysis of more than 23 million participants. Environ Health Prev Med 2021, 26, (1), 1-14.

15. Huangfu, P.; Atkinson, R., Long-term exposure to $\mathrm{NO}_{2}$ and $\mathrm{O}_{3}$ and all-cause and respiratory mortality: A systematic review and meta-analysis. Environ Int 2020, 144, 105998.

16. Atkinson, R. W.; Butland, B. K.; Dimitroulopoulou, C.; Heal, M. R.; Stedman, J. R.; Carslaw, N.; Jarvis, D.; Heaviside, C.; Vardoulakis, S.; Walton, H.; Anderson, H. R., Long-term exposure to ambient ozone and mortality: a quantitative systematic review and meta-analysis of evidence from cohort studies. BMJ Open 2016, 6, (2), e009493.

17. Shen, H.; Sun, Z.; Chen, Y.; Russell, A. G.; Hu, Y.; Odman, M. T.; Qian, Y.; Archibald, A. T.; Tao, S., A novel method for ozone isopleth construction and diagnosis for ozone control strategy of China cities. Environ Sci Technol 2021.

18. Sun, Z; Archibald, A. T., Multi-stage Ensemble-learning-based Model Fusion for Surface Ozone Simulations: A Focus on CMIP6 Models. Environmental Science and Ecotechnology 2021, 8, 100124. 
19. Schultz, M. G.; Schroder, S.; Lyapina, O.; Cooper, O. R.; Galbally, I.; Petropavlovskikh, I.; von Schneidemesser, E.; Tanimoto, H.; Elshorbany, Y.; Naja, M.; Seguel, R. J.; Dauert, U.; Eckhardt, P.; Feigenspan, S.; Fiebig, M.; Hjellbrekke, A. G.; Hong, Y. D.; Kjeld, P. C.; Koide, H.; Lear, G.; Tarasick, D.; Ueno, M.; Wallasch, M.; Baumgardner, D.; Chuang, M. T.; Gillett, R.; Lee, M.; Molloy, S.; Moolla, R.; Wang, T.; Sharps, K.; Adame, J. A.; Ancellet, G.; Apadula, F.; Artaxo, P.; Barlasina, M. E.; Bogucka, M.; Bonasoni, P.; Chang, L.; Colomb, A.; Cuevas-Agullo, E.; Cupeiro, M.; Degorska, A.; Ding, A. J.; FrHlich, M.; Frolova, M.; Gadhavi, H.; Gheusi, F.; Gilge, S.; Gonzalez, M. Y.; Gros, V.; Hamad, S. H.; Helmig, D.; Henriques, D.; Hermansen, O.; Holla, R.; Hueber, J.; Im, U.; Jaffe, D. A.; Komala, N.; Kubistin, D.; Lam, K. S.; Laurila, T.; Lee, H.; Levy, I.; Mazzoleni, C.; Mazzoleni, L. R.; McClure-Begley, A.; Mohamad, M.; Murovec, M.; Navarro-Comas, M.; Nicodim, F.; Parrish, D.; Read, K. A.; Reid, N.; Ries, N. R. L.; Saxena, P.; Schwab, J. J.; Scorgie, Y.; Senik, I.; Simmonds, P.; Sinha, V.; Skorokhod, A. I.; Spain, G.; Spangl, W.; Spoor, R.; Springston, S. R.; Steer, K.; Steinbacher, M.; Suharguniyawan, E.; Torre, P.; Trickl, T.; Lin, W. L.; Weller, R.; Xu, X. B.; Xue, L. K.; Ma, Z. Q., Tropospheric Ozone Assessment Report: Database and metrics data of global surface ozone observations. Elem Sci Anthrop 2017, 5, 58-83.

20. Institute for Health Metrics and Evaluation (IHME), GBD 2019 Cause and Risk Summary: Ambient Ozone Pollution. In IHME, University of Washington: Seattle, USA, 2020.

21. Guyatt, G. H.; Oxman, A. D.; Vist, G. E.; Kunz, R.; Falck-Ytter, Y.; Alonso-Coello, P.; Schunemann, H. J.; Group, G. W., GRADE: an emerging consensus on rating quality of evidence and strength of recommendations. $B M J$ 2008, 336, (7650), 924-6.

22. Guyatt, G.; Oxman, A. D.; Akl, E. A.; Kunz, R.; Vist, G.; Brozek, J.; Norris, S.; Falck-Ytter, Y.; Glasziou, P.; DeBeer, H.; Jaeschke, R.; Rind, D.; Meerpohl, J.; Dahm, P.; Schunemann, H. J., GRADE guidelines: 1. Introduction-GRADE evidence profiles and summary of findings tables. J Clin Epidemiol 2011, 64, (4), 383-94.

23. Duval, S.; Tweedie, R., A nonparametric "trim and fill" method of accounting for publication bias in metaanalysis. J Am Stat Assoc 2000, 95, (449), 89-98.

24. Sun, H. Z.; Shin, Y. M.; Xia, M.; Ke, S.; Yuan, L.; Guo, Y.; Archibald, A. T., Spatial Resolved Surface Ozone with Urban and Rural Differentiation during 1990-2019: A Space-time Bayesian Neural Network Downscaler. Environ Sci Technol 2021.

25. Krupa, S.; McGrath, M. T.; Andersen, C. P.; Booker, F. L.; Burkey, K. O.; Chappelka, A. H.; Chevone, B. I.; Pell, E. J.; Zilinskas, B. A., Ambient Ozone and Plant Health. Plant Dis 2001, 85, (1), 4-12.

26. Finlayson-Pitts, B.; Pitts Jr, J., Atmospheric chemistry of tropospheric ozone formation: scientific and regulatory implications. J Air Manag Waste Assoc 1993, 43, (8), 1091-1100.

27. Fleming, Z. L.; Doherty, R. M.; Von Schneidemesser, E.; Malley, C. S.; Cooper, O. R.; Pinto, J. P.; Colette, A.; Xu, X.; Simpson, D.; Schultz, M. G.; Lefohn, A. S.; Hamad, S.; Moolla, R.; Solberg, S.; Feng, Z., Tropospheric Ozone Assessment Report: Present-day ozone distribution and trends relevant to human health. Elem Sci Anth 2018, 6 , 12.

28. Griffiths, P. T.; Murray, L. T.; Zeng, G.; Archibald, A. T.; Emmons, L. K.; Galbally, I.; Hassler, B.; Horowitz, L. W.; Keeble, J.; Liu, J.; Moeini, O.; Naik, V.; amp; apos; Connor, F. M.; Shin, Y. M.; Tarasick, D.; Tilmes, S.; Turnock, S. T.; Wild, O.; Young, P. J.; Zanis, P., Tropospheric ozone in CMIP6 Simulations. Atmos Chem Phys 2021, 21, 4187-4218.

29. Archibald, A. T.; O'Connor, F. M.; Abraham, N. L.; Archer-Nicholls, S.; Chipperfield, M. P.; Dalvi, M.; Folberth, G. A.; Dennison, F.; Dhomse, S. S.; Griffiths, P. T.; Hardacre, C.; Hewitt, A. J.; Hill, R.; Johnson, C. E.; Keeble, J.; Köhler, M. O.; Morgenstern, O.; Mulchay, J. P.; Ordóñez, C.; Pope, R. J.; Rumbold, S.; Russo, M. R.; Savage, N.; Sellar, A.; Stringer, M.; Turnock, S.; Wild, O.; Zeng, G., Description and evaluation of the UKCA stratospheretroposphere chemistry scheme (StratTrop vn 1.0) implemented in UKESM1. Geosci Model Dev 2019, 13, (3), 1223-1266.

30. Tong, L.; Zhang, H.; Yu, J.; He, M.; Xu, N.; Zhang, J.; Qian, F.; Feng, J.; Xiao, H., Characteristics of surface ozone and nitrogen oxides at urban, suburban and rural sites in Ningbo, China. Atmos Res 2017, 187, 57-68.

31. U.S. EPA Air Quality Criteria For Ozone and Related Photochemical Oxidants (Final Report, 2006); U.S. Environmental Protection Agency: Washington, DC, 2006.

32. DerSimonian, R.; Laird, N., Meta-analysis in clinical trials. Control Clin Trials 1986, 7, (3), 177-88.

33. Higgins, J. P.; Thompson, S. G.; Deeks, J. J.; Altman, D. G., Measuring inconsistency in meta-analyses. BMJ 2003, 327, (7414), 557-60.

34. Burnett, R. T.; Pope, C. A., 3rd; Ezzati, M.; Olives, C.; Lim, S. S.; Mehta, S.; Shin, H. H.; Singh, G.; Hubbell, B.; Brauer, M.; Anderson, H. R.; Smith, K. R.; Balmes, J. R.; Bruce, N. G.; Kan, H.; Laden, F.; Pruss-Ustun, A.; Turner, M. C.; Gapstur, S. M.; Diver, W. R.; Cohen, A., An integrated risk function for estimating the global burden of disease attributable to ambient fine particulate matter exposure. Environ Health Perspect 2014, 122, (4), $397-403$. 
35. Abbey, D. E.; Nishino, N.; McDonnell, W. F.; Burchette, R. J.; Knutsen, S. F.; Lawrence Beeson, W.; Yang, J. X., Long-term inhalable particles and other air pollutants related to mortality in nonsmokers. Am J Respir Crit Care Med 1999, 159, (2), 373-82.

36. Lipfert, F. W.; Wyzga, R. E.; Baty, J. D.; Miller, J. P., Traffic density as a surrogate measure of environmental exposures in studies of air pollution health effects: Long-term mortality in a cohort of US veterans. Atmos Environ 2006, 40, (1), 154-169.

37. Jerrett, M.; Burnett, R. T.; Pope, C. A., $3^{\text {rd }}$; Ito, K.; Thurston, G.; Krewski, D.; Shi, Y.; Calle, E.; Thun, M., Longterm ozone exposure and mortality. N Engl J Med 2009, 360, (11), 1085-95.

38. Krewski, D.; Jerrett, M.; Burnett, R. T.; Ma, R.; Hughes, E.; Shi, Y.; Turner, M. C.; Pope III, C. A.; Thurston, G.; Calle, E. E., Extended follow-up and spatial analysis of the American Cancer Society study linking particulate air pollution and mortality. Health Effects Institute Boston, MA: 2009.

39. Smith, K. R.; Jerrett, M.; Anderson, H. R.; Burnett, R. T.; Stone, V.; Derwent, R.; Atkinson, R. W.; Cohen, A.; Shonkoff, S. B.; Krewski, D.; Pope, C. A., $3^{\text {rd }}$ Thun, M. J.; Thurston, G., Public health benefits of strategies to reduce greenhouse-gas emissions: health implications of short-lived greenhouse pollutants. Lancet 2009, 374, (9707), 2091-2103.

40. Lipsett, M. J.; Ostro, B. D.; Reynolds, P.; Goldberg, D.; Hertz, A.; Jerrett, M.; Smith, D. F.; Garcia, C.; Chang, E. T.; Bernstein, L., Long-term exposure to air pollution and cardiorespiratory disease in the California teachers study cohort. Am J Respir Crit Care Med 2011, 184, (7), 828-35.

41. Zanobetti, A.; Schwartz, J., Ozone and survival in four cohorts with potentially predisposing diseases. Am J Respir Crit Care Med 2011, 184, (7), 836-41.

42. Carey, I. M.; Atkinson, R. W.; Kent, A. J.; van Staa, T.; Cook, D. G.; Anderson, H. R., Mortality associations with long-term exposure to outdoor air pollution in a national English cohort. Am J Respir Crit Care Med 2013, 187, (11), 1226-33.

43. Jerrett, M.; Burnett, R. T.; Beckerman, B. S.; Turner, M. C.; Krewski, D.; Thurston, G.; Martin, R. V.; van Donkelaar, A.; Hughes, E.; Shi, Y.; Gapstur, S. M.; Thun, M. J.; Pope, C. A., $3^{\text {rd }}$, Spatial analysis of air pollution and mortality in California. Am J Respir Crit Care Med 2013, 188, (5), 593-9.

44. Bentayeb, M.; Wagner, V.; Stempfelet, M.; Zins, M.; Goldberg, M.; Pascal, M.; Larrieu, S.; Beaudeau, P.; Cassadou, S.; Eilstein, D., Association between long-term exposure to air pollution and mortality in France: a 25year follow-up study. Environ Int 2015, 85, 5-14.

45. Crouse, D. L.; Peters, P. A.; Hystad, P.; Brook, J. R.; van Donkelaar, A.; Martin, R. V.; Villeneuve, P. J.; Jerrett, M.; Goldberg, M. S.; Pope III, C. A., Ambient $\mathrm{PM}_{2.5}, \mathrm{O}_{3}$, and $\mathrm{NO}_{2}$ exposures and associations with mortality over 16 years of follow-up in the Canadian Census Health and Environment Cohort (CanCHEC). Environ Health Perspect 2015, 123, (11), 1180-1186.

46. Tonne, C.; Halonen, J. I.; Beevers, S. D.; Dajnak, D.; Gulliver, J.; Kelly, F. J.; Wilkinson, P.; Anderson, H. R., Long-term traffic air and noise pollution in relation to mortality and hospital readmission among myocardial infarction survivors. Int J Hyg Environ Health 2016, 219, (1), 72-78.

47. Turner, M. C.; Jerrett, M.; Pope, C. A., $3^{\text {rd }}$; Krewski, D.; Gapstur, S. M.; Diver, W. R.; Beckerman, B. S.; Marshall, J. D.; Su, J.; Crouse, D. L.; Burnett, R. T., Long-Term Ozone Exposure and Mortality in a Large Prospective Study. Am J Respir Crit Care Med 2016, 193, (10), 1134-42.

48. Weichenthal, S.; Pinault, L. L.; Burnett, R. T., Impact of oxidant gases on the relationship between outdoor fine particulate air pollution and nonaccidental, cardiovascular, and respiratory mortality. Sci Rep 2017, 7, (1), 1-10.

49. Cakmak, S.; Hebbern, C.; Pinault, L.; Lavigne, E.; Vanos, J.; Crouse, D. L.; Tjepkema, M., Associations between long-term $\mathrm{PM}_{2.5}$ and ozone exposure and mortality in the Canadian Census Health and Environment Cohort (CANCHEC), by spatial synoptic classification zone. Environ Int 2018, 111, 200-211.

50. Di, Q.; Wang, Y.; Zanobetti, A.; Wang, Y.; Koutrakis, P.; Choirat, C.; Dominici, F.; Schwartz, J. D., Air Pollution and Mortality in the Medicare Population. $N$ Engl J Med 2017, 376, (26), 2513-2522.

51. Hvidtfeldt, U. A.; Sorensen, M.; Geels, C.; Ketzel, M.; Khan, J.; Tjonneland, A.; Overvad, K.; Brandt, J.; Raaschou-Nielsen, O., Long-term residential exposure to $\mathrm{PM}_{2.5}, \mathrm{PM}_{10}$, black carbon, $\mathrm{NO}_{2}$, and ozone and mortality in a Danish cohort. Environ Int 2019, 123, 265-272.

52. Kazemiparkouhi, F.; Eum, K. D.; Wang, B.; Manjourides, J.; Suh, H. H., Long-term ozone exposures and causespecific mortality in a US Medicare cohort. J Expo Sci Environ Epidemiol 2020, 30, (4), 650-658.

53. Lim, C. C.; Hayes, R. B.; Ahn, J.; Shao, Y.; Silverman, D. T.; Jones, R. R.; Garcia, C.; Bell, M. L.; Thurston, G. D., Long-Term Exposure to Ozone and Cause-Specific Mortality Risk in the United States. Am J Respir Crit Care Med 2019, 200, (8), 1022-1031.

54. Paul, L. A.; Burnett, R. T.; Kwong, J. C.; Hystad, P.; van Donkelaar, A.; Bai, L.; Goldberg, M. S.; Lavigne, E.; 
Copes, R.; Martin, R. V., The impact of air pollution on the incidence of diabetes and survival among prevalent diabetes cases. Environ Int 2020, 134, 105333.

55. Malley, C. S.; Henze, D. K.; Kuylenstierna, J. C. I.; Vallack, H. W.; Davila, Y.; Anenberg, S. C.; Turner, M. C.; Ashmore, M. R., Updated Global Estimates of Respiratory Mortality in Adults $\geq 30$ Years of Age Attributable to Long-Term Ozone Exposure. Environ Health Perspect 2017, 125, (8), 087021.

56. Anenberg, S. C.; Horowitz, L. W.; Tong, D. Q.; West, J. J., An estimate of the global burden of anthropogenic ozone and fine particulate matter on premature human mortality using atmospheric modeling. Environ Health Perspect 2010, 118, (9), 1189-1195.

57. Fann, N.; Lamson, A. D.; Anenberg, S. C.; Wesson, K.; Risley, D.; Hubbell, B. J., Estimating the national public health burden associated with exposure to ambient $\mathrm{PM}_{2.5}$ and ozone. Risk Anal 2012, 32, (1), 81-95.

58. Silva, R. A.; West, J. J.; Zhang, Y.; Anenberg, S. C.; Lamarque, J.-F.; Shindell, D. T.; Collins, W. J.; Dalsoren, S.; Faluvegi, G.; Folberth, G., Global premature mortality due to anthropogenic outdoor air pollution and the contribution of past climate change. Environ Res Lett 2013, 8, (3), 034005.

59. West, J. J.; Smith, S. J.; Silva, R. A.; Naik, V.; Zhang, Y.; Adelman, Z.; Fry, M. M.; Anenberg, S.; Horowitz, L. W.; Lamarque, J.-F., Co-benefits of mitigating global greenhouse gas emissions for future air quality and human health. Nat Clim Change 2013, 3, (10), 885-889.

60. Yu, P.; Guo, S.; Xu, R.; Ye, T.; Li, S.; Sim, M.; Abramson, M. J.; Guo, Y., Cohort studies of long-term exposure to outdoor particulate matter and risks of cancer: A systematic review and meta-analysis. The Innovation 2021, 100143.

61. Meng, X.; Liu, C.; Chen, R.; Sera, F.; Vicedo-Cabrera, A. M.; Milojevic, A.; Guo, Y.; Tong, S.; Coelho, M.; Saldiva, P. H. N.; Lavigne, E.; Correa, P. M.; Ortega, N. V.; Osorio, S.; Garcia; Kysely, J.; Urban, A.; Orru, H.; Maasikmets, M.; Jaakkola, J. J. K.; Ryti, N.; Huber, V.; Schneider, A.; Katsouyanni, K.; Analitis, A.; Hashizume, M.; Honda, Y.; Ng, C. F. S.; Nunes, B.; Teixeira, J. P.; Holobaca, I. H.; Fratianni, S.; Kim, H.; Tobias, A.; Iniguez, C.; Forsberg, B.; Astrom, C.; Ragettli, M. S.; Guo, Y. L.; Pan, S. C.; Li, S.; Bell, M. L.; Zanobetti, A.; Schwartz, J.; Wu, T.; Gasparrini, A.; Kan, H., Short term associations of ambient nitrogen dioxide with daily total, cardiovascular, and respiratory mortality: multilocation analysis in 398 cities. BMJ 2021, 372, n534.

62. Yu, K.; Lv, J.; Qiu, G.; Yu, C.; Guo, Y.; Bian, Z.; Yang, L.; Chen, Y.; Wang, C.; Pan, A.; Liang, L.; Hu, F. B.; Chen, Z.; Li, L.; Wu, T.; China Kadoorie Biobank, S., Cooking fuels and risk of all-cause and cardiopulmonary mortality in urban China: a prospective cohort study. Lancet Glob Health 2020, 8, (3), e430-e439. 